\title{
ANÁLISIS MACROMORFOLÓGICO Y CITOGENÉTICO DEL GÉNERO Cosmos (Asteraceae, Coreopsideae), con una Clave PARA SU IDENTIFICACIÓN
}

\author{
Arturo Castro-Castro ${ }^{1}$, Georgina Vargas-Amado², Mollie Harker ${ }^{2}$ y Aarón RodríGuez ${ }^{2,3}$ \\ ${ }^{1}$ Centro Universitario de Ciencias Biológicas y Agropecuarias, Universidad de Guadalajara, Zapopan, Jalisco, México \\ ${ }^{2}$ Herbario Luz María Villarreal de Puga del Instituto de Botánica (IBUG), Centro Universitario de Ciencias Biológicas y \\ Agropecuarias, Universidad de Guadalajara, Zapopan, Jalisco, México \\ ${ }^{3}$ Autor para la correspondencia: rca08742@cucba.udg.mx
}

\begin{abstract}
Resumen: Cosmos es un género que tiene sus límites de distribución natural en América, y México representa su centro de diversificación. Su repartición geográfica es interesante, pues algunas especies tienen una amplia distribución y han sido intensamente recolectadas, mientras que otras, debido a su distribución restringuida, son poco conocidas. Este hecho ha generado incomprensión sobre su variabilidad morfológica y sus límites infragenéricos, interespecíficos, e incluso, intergenéricos en la tribu Coreopsideae. En Cosmos, la variabilidad en los niveles de ploidía entre especies y entre poblaciones de una misma especie, sugiere que la poliploidía y aneuploidía han jugado un papel importante en la especiación del grupo. Ante este escenario, se aportan datos macromorfológicos para el entendimiento de los límites intergenéricos, de los grupos infragenéricos y de las especies. Además, se incluye información acerca de la variabilidad cromosómica y distribución geográfica de Cosmos. Por último, se brinda una clave para la identificación de todas las especies.
\end{abstract}

Palabras clave: endemismo, México, poliploidía, xilopodio.

\begin{abstract}
The genus Cosmos is restricted to the Americas, and Mexico represents its center of diversification. Some species have a wide distribution and have been intensively collected, whereas others, due to their narrow distribution, are poorly known. This has generated a poor understanding of its morphological variability and infrageneric and interspecific limits, as well as confusion at the intergeneric level within tribe Coreopsideae. Polyploidy and aneuploidy have played an important role in the speciation of the group. The ploidy level variation can be seen between species, as well as in populations of the same species. Macromorphological data are used to support recognition of intergeneric limits, infrageneric groups, and species. Evidence of chromosome number variability and geographic distribution information for Cosmos is also included. These data are fundamental for the taxonomic understanding of the genus. A key for the identification of all species of Cosmos is provided.
\end{abstract}

Keywords: endemism, Mexico, polyploidy, xylopodium.

L a circunscripción de la tribu Coreopsideae Lindl. (Asteraceae) ha sido propuesta en múltiples formas (Panero y Funk, 2002; Kimball y Crawford, 2004; Mort et al., 2008; Panero, 2007; Crawford et al., 2009). Crawford y Stuessy (1981), Robinson (1981) y Ryding y Bremer (1992) la reconocieron por la presencia de dos series de filarias distintas, con canales resiníferos conspicuos en la serie interna y la presencia de pigmentos flavonoides. De acuerdo con Panero y Funk (2002) y Crawford et al. (2009), la tribu integra a 24 géneros y cerca de 600 especies. Como alternativa, Panero (2007) reconoce 30 géneros y alrededor de 550 especies.
Aunque es cosmopolita, su mayor diversidad se encuentra en América, donde los géneros Bidens L., Coreopsis L., Cosmos Cav. y Dahlia Cav. representan el $85 \%$ de su diversidad. México es diverso en Coreopsideae y concentra el $50 \%$ de su riqueza en los géneros Bidens, Chrysanthellum Rich., Coreocarpus Benth., Coreopsis, Cosmos, Dahlia, Dicranocarpus A.Gray, Goldmanella (Greenm.) Greenm., Henricksonia B.L.Turner, Heterosperma Cav., Hidalgoa La Llave \& Lex. y Thelesperma Less.

Un caso particular de la diversidad de Coreopsideae en América y en México es Cosmos, grupo que concentra a 
35 especies (Castro-Castro et al., 2013; Cuadro 1). El género tiene sus límites de distribución natural en América. Se desarolla desde los $38.1^{\circ} \mathrm{N}$, en el centro del estado de Colorado, en E.U.A., hasta los $26.7^{\circ} \mathrm{S}$, en las provincias de Catamarca y Tucumán en el noroeste de Argentina (VargasAmado et al., 2013; Cuadro 1). El género ha diversificado y colonizado una gran variedad de ambientes y constituye un elemento importante en el paisaje de numerosas formaciones vegetales. Cosmos parviflorus (Jacq.) Pers. tiene la distribución más boreal, mientras que $C$. caudatus Kunth y $C$. peucedanifolius Wedd. crecen en las regiones más australes. En un contexto biogeográfico y evolutivo, C. peucedanifolius se distingue por ser endémica a Sudamérica (Cuadro 1). Por su parte C. caudatus, C. pacificus Melchert y C. sulphureus Cav. se encuentran en las islas del Caribe y planicies costeras de México, Centroamérica y Sudamérica. Además, C. atrosanguineus (Hook.) A.Voss, C. bipinnatus Cav., $C$. caudatus y $C$. sulphureus se cultivan y han naturalizado en el trópico y subtrópico.

México representa el centro de diversificación de Cosmos. En su territorio crecen 34 especies (94\% de la diversidad), de las cuales, 32 (86\%) son endémicas (Cuadro 1). Los estados de Durango, Guerrero, Jalisco y México son las entidades con mayor diversidad y endemismos (VargasAmado et al., 2013). Jalisco es el estado con la mayor riqueza, con 19 taxa, seguido de Durango con 12 y el Estado de México y Guerrero con 11 cada uno (Vargas-Amado et al., 2013; Cuadro 1). Su repartición geográfica es interesante, Cosmos bipinnatus, $C$. caudatus, $C$. crithmifolius Kunth, $C$. parviflorus, C. peucedanifolius y C. sulphureus tienen una amplia distribución y han sido intensamente recolectadas, mientras que $C$. deficiens (Sherff) Melchert, $C$. juxtlahuacensis Panero \& J.L.Villaseñor, C. longipetiolatus Melchert, C. mattfeldii Sherff, C. schaffneri Sherff y C. sherffii Melchert, debido a su estrecho endemismo o por su distribución irregular y localizada, casi no se han colectado, sino en tiempos recientes (Vargas-Amado et al., 2013). Este fenómeno es tan marcado que se puede suponer la existencia de especies aún no descritas.

Sherff $(1932,1955)$ estudió la taxonomía de Cosmos. Con base en los hábitos de crecimiento, color de las flores liguladas y la morfología de los aquenios, él estableció a $C$. sección Cosmos, $C$. sección Discopoda (DC.) Sherff, $C$. sección Klibea Sherff y $C$. sección Mesinenia Sherff. En la sección Cosmos incluyó a ocho especies: "hierbas, anuales y con flores liguladas anaranjadas, amarillas, rosadas, blancas, etc., aquenios por lo común más o menos tetragonales, rostrados o errostrados, aristados, aristas retrorso barbadas, glabros y no alados". Por otro lado, en la sección Discopoda circunscribió 13 especies: "hierbas perennes, de raíces tuberoso fasciculadas, ascendentes o erectas. Hojas caulinares o basales. Flores liguladas rara vez blanco rosadas, en su mayoría rosadas, violadas, lilas, púrpuras o atropurpúreas. Aquenios de base atenuada, irregular, areolada, rostro elon- gado, aristas retrorso barbadas". En la sección Mesinenia limitó a cinco: "hierbas perennes, erectas, base leñosa y en consecuencia más o menos engrosada. Flores liguladas blancas, rosadas, violadas, etc. Aquenios por lo general tetragonales, nunca alados, rostro atenuado a elongado, aristados, retrorso barbados". En contraste, integró en la sección Klibea a tres especies [C. blakei (Sherff) Melchert, $C$. exiguus A.Gray y C. steyermarkii Sherff] por ser: "hierbas probablemente anuales. Flores liguladas, rosadas o blancas. Aquenios fuertemente aplanados, alados o no alados, rostrados, aristados, aristas por completo híspidas". Sin embargo, con base en la presencia de flavonoides tipo chalconas y auronas en sus hojas, lígulas amarillas, bicolores, con máculas rojizas en su base, filamentos glabros y aquenios con tres surcos longitudinales en cada una de sus caras, los miembros de Cosmos sección Klibea fueron transferidos a Bidens (Melchert, 1975).

La filogenia de Cosmos no ha sido resuelta. Evidencia morfológica (Ryding y Bremer, 1992) y molecular (Kimball y Crawford, 2004; Mort et al., 2008; Muñiz-Mendoza, 2008) apoyan la monofilia del género. Los filamentos pubescentes y los aquenios tetrangulares con uno o dos surcos longitudinales por cara son caracteres sinapomórficos. Además, con distintas fuentes de evidencia se reconocen a Bidens (Tadesse et al., 2001), Coreocarpus (Kimball y Crawford, 2004; Mort et al., 2008; Muñiz-Mendoza, 2008) y Heterosperma (Ryding y Bremer, 1992) como su grupo hermano. Sin embargo, estas hipótesis deben ser consideradas con mesura, debido al incompleto número de géneros incluidos, el reducido número de especies de Cosmos analizadas y el soporte débil de las relaciones filogenéticas identificadas.

Se ha sugerido que reducciones y duplicaciones cromosómicas han favorecido la diversificación de Coreopsideae (Robinson et al., 1981; Crawford et al., 2009; Semple y Watanabe, 2009). De acuerdo con Robinson et al. (1981) y Smith (1975), los números cromosómicos básicos $(x)$ más comunes en la tribu son $x=12$ ó 14 . Sin embargo, Crawford et al. (2009) determinaron el valor de $x=16$ como número básico, argumentando distintos eventos de aneuploidía. Un escenario similar ocurre en Cosmos, en donde distintos eventos de poliploidía y aneuploidía se han asociado con su evolución. Melchert (1968) correlacionó la morfología con los datos cromosómicos y sugirió la existencia de dos complejos. La primera dicotomía evolutiva originó a las secciones Cosmos y Discopoda por un lado y a Mesinenia por el otro. Las especies sufrútices de la sección Mesinenia poseen un número cromosómico básico $x=11(n=11,22,33)$. En contraste, las hierbas perennes de la sección Discopoda y las anuales de la sección Cosmos poseen un número base de $x=12(n=12,24,36,48)$.

La morfología de Cosmos es muy variable y no ha sido analizada. La labilidad de distintas estructuras vegetativas y reproductivas ha generado alrededor de 80 sinonimias entre Cosmos, Bidens, Coreopsis y Dahlia. De la misma forma, 
la variabilidad morfológica de Cosmos ha dado lugar a inconsistencias en la definición de los grupos infragenéricos propuestos por Sherff (1932). Ante este contexto, el objetivo del presente trabajo fue analizar la variabilidad macromorfológica y cromosómica en Cosmos, como punto de partida para el entendimiento preciso de sus límites intergenéricos, infragenéricos e interespecíficos.

Una clave dicotómica es útil para la identificación de los taxa. Sherff $(1932,1955)$ generó una para la identificación de 20 especies. Por su parte, Melchert (2010b) propuso otra, pero además de no incluir a todas las especies, tiene problemas en algunos dilemas. Por ejemplo, se omiten o no siguen un mismo orden los caracteres entre los pares $6,7,8,11,17$, 19. El número del par 22 está duplicado. Los caracteres de la copla 3 se encuentran repetidos. Existen incosistencias en el uso del color de las flores del disco entre los dilemas 22, 25, 26,28 y 29. Otro caso es el conjunto de coplas para separar a las especies de Cosmos sección Mesinenia, en el que se incluye a $C$. juxtlahuacensis (Cosmos sección Discopoda: 15, 15'). Aún más, en los pares 8,22 y 27 el redireccionamiento hacia otro par es incorrecto. Por tal razón, aquí se presenta una clave enmendada y que incluye a todas las especies ahora conocidas.

\section{Materiales y métodos}

Los datos morfológicos y geográficos fueron obtenidos de ejemplares de herbario depositados en BAA, CIIDIR, ENCB, GUADA, HCIB, HUMO, IBUG, IEB, JUA, LIL, LP, LPAG, LPB, LPC, MCNS, MEXU, MO, MOL, NY, TEX, UAGC, USZ, XAL y ZEA (acrónimos según Thiers, 2013). Asimismo, especímenes tipo fueron consultados por medio de los sitios virtuales de los herbarios B, F, G, GH, IA, K, MICH, NY, P, TEX y US (acrónimos según Thiers, 2013). Además, de 2009 a 2013 fueron recolectadas todas las especies en sus localidades tipo y otros sitios de presencia esperada. La colección principal ha sido depositada en el herbario IBUG y los duplicados fueron enviados a CIIDIR, ENCB, IEB, MEXU, XAL y ZEA.

Por otro lado, fueron revisados los protólogos y otras descripciones de las especies incluidas en monografías y trabajos florísticos (De Candolle, 1836; Greenman, 1904; Robinson, 1909; Sherff, 1917, 1923, 1925, 1926 1929, 1930, 1932, 1936, 1937, 1955, 1959, 1962, 1964; Melchert, 1967, 1968, 1975, 1976, 1990a, b, c, 2010b; McVaugh, 1984; Melchert y Turner, 1990; Panero y Villaseñor, 1996; Strother, 1999; Hind y Fay, 2003; Hind, 2005; Rzedowski y Calderón de Rzedowski, 2008; Novara y Gutiérrez, 2010). También, se hicieron ilustraciones y se tomaron fotografías de las estructuras que demuestran la variablidad morfológica. Las definiciones sobre los distintos caracteres morfológicos siguen los conceptos de Font Quer (1953), Moreno (1984) y Harris y Harris (1994).

La información cromosómica de Cosmos fue obtenida de
Melchert (1968, 1990a, b, 2010a), Keil y Stuessy (1975), Robinson et al. (1981), Crawford (1982), Strother (1983), Sundberg et al. (1986), Carr et al. (1999), Strother y Panero (2001) y Castro-Castro et al. (datos sin publicar). También se utilizó la base de datos Index to Chromosome Numbers in Asteraceae (Watanabe, 2013).

\section{Resultados}

A partir del análisis de la variabilidad morfológica y distribución geográfica de 3,400 ejemplares de herbario, y la recolección y estudio de todas las especies en campo, se coincidió con Sherff (1932) en la definición de los grupos infragenéricos en Cosmos.

Cosmos sección Cosmos. Hierbas anuales, 0.5-2.5 m de altura. Raíz axonomorfa (Figura 1A). Tallos pubescentes (Cosmos bipinnatus, C. parviflorus y C. sulphureus), glabros (C. pacificus) o variables (C. caudatus), hexangonales o teretes (C. parviflorus). Pecíolos de 2-12 cm de longitud, alados y pericládicos. Hojas caulinares, membranáceas, 1-2 pinnatisectas (C. bipinnatus, C. caudatus y C.parviflorus) o 3 pinnatisectas (C. pacificus y C. sulphureus), pubescentes (C. bipinnatus y $C$. sulphureus) o glabras (C. caudatus, $C$. pacificus y $C$. parviflorus). Segmentos de las hojas enteros o lobados, lineares a filiformes $(C$. bipinnatus y $C$. parviflorus) u oblongos a elíptico-ovados o lineares (C. caudatus, C. pacificus y $C$. sulphureus) y de margen escabriúsculo. Capítulos reunidos en un multi-dicasio (cima compuesta) folioso y ramificado por arriba de la mitad del eje principal. Pedúnculos 15-30 cm de longitud (Figura 2A). Involucro campanulado a subhemisférico. Filarias externas ocho, lanceoladas, triangulares, ovadas o subuladas, agudas a acuminado-caudadas, de color verdes, glabrescentes o glabras (C. parviflorus), con nervaduras oscuras en su cara dorsal, adpresas a las filarias internas o ligeramente extendidas (Figura 3P, $\mathrm{O}, \mathrm{U}, \mathrm{V})$; internas ocho, oblongas a elípticas u obovadas, agudas, erectas, translúcidas o del mismo color que las lígulas pero con el margen hialino, glabras (Figura 3P, Q, U, V). Páleas lanceoladas, translúcidas, glabras. Flores liguladas ocho (ocasionalmente 10-12 en C. bipinnatus), ágamas; lígulas ovadas, obovadas a oblanceoladas, de color blanco-violáceo (C. bipinnatus, $C$. caudatus, $C$. pacificus y C. parviflorus) o anaranjado (C. sulphureus), con 3-5 nervaduras pilosas en su cara dorsal (Figura 4). Flores del disco (5-)10 (C. pacificus y C. sulphureus) a 120 (C. bipinnatus), infundibuliformes a hipocrateriformes, 5-lobadas, glabras o puberulentas en el tubo y la garganta, de color amarillo (Figuras 5, 6). Androceo fanerostémono, de color café oscuro; anteras sagitadas o redondeadas, apéndices lanceolados a ovados, caudados a redondeados y con una prolongación evidente del conectivo (Figura 5). Polen de color amarillo. Estigma bifurcado, ramas seríceas en su porción media a terminal, provistas de apéndices caudados o cirrosos (Figura 

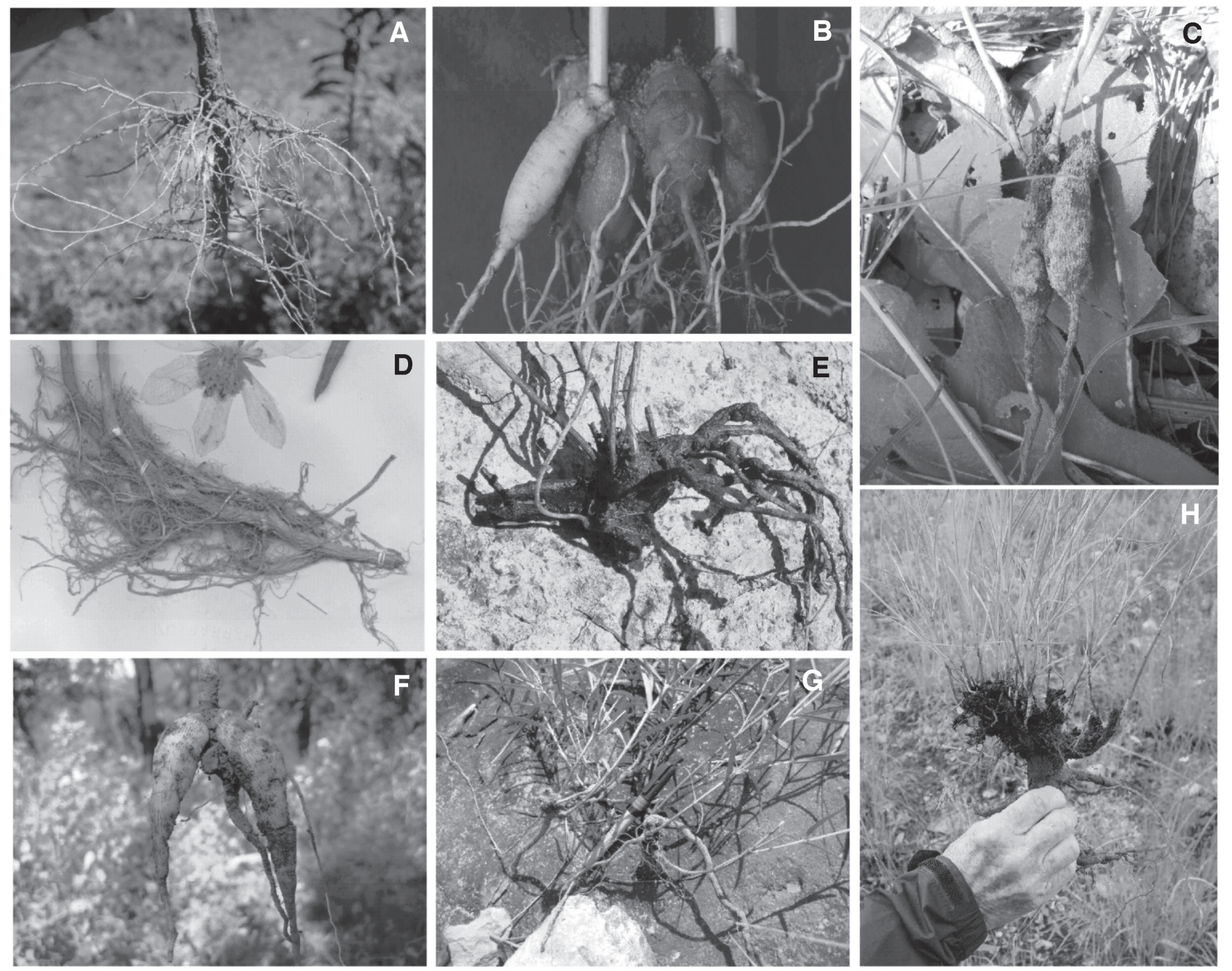

Figura 1. Raíces y mecanismos de perennidad desarrollados en el género Cosmos. A) raíz axonomorfa típica de especies anuales (Cosmos sección Cosmos); B, C, F) rizoma corto con raíces tuberosas en Cosmos sección Discopoda; D) rizoma horizontal con raíces adventicias (Cosmos sección Discopoda); E, G, H) rizoma vertical con raíces adventicias crasas y fibrosas a manera de un xilopodio en Cosmos sección Mesinenia. A) C. caudatus; B) C.nitidus; C) C. ramirezianus; D) C. mcvaughii; E) C. intercedens; F) C. scabiosoides; G) C. linearifolius; H) C. ochroleucoflorus. Créditos: Georgina Vargas-Amado (A, B); Arturo Castro-Castro (C-H).

5A-D). Aquenios lineares a fusiformes, tetragonales, con un surco longitudinal en cada lado o ligeramente aplanados y entonces 4-costillados, de color café oscuro a negro, glabros o setulosos, con rostro de 0.5-6(-10) $\mathrm{mm}$ de longitud. Vilano de 2-6 aristas retrorso barbeladas, 3-5 mm de longitud, a veces caedizas o ausentes. Carpóforo discoide (Figura 6). Receptáculo plano o ligeramente convexo. El número cromosómico básico es $x=12$, con cuatro especies diploides y una tetraploide (Cuadro 1).

Cosmos sección Discopoda. Hierbas perennes, 0.3-1.5 m de altura. Rizomas cortos con raíces tuberosas, rizomas largos que producen plantas en apariencia independientes (Cosmos diversifolius Otto ex Knowles \& Westc.) o rizoma largo y con raíces fibrosas (C. mcvaughii Sherff; Figura 1B, C, D, F). Tallos glabros o ligeramente pubescentes, lisos, teretes o hexagonales (C. ramirezianus Art.Castro, M.Harker \& Aaron Rodr.). La variación foliar en Cosmos sección Discopoda se resume en el Apéndice 2. Capítulos solitarios a manera de un escapo o reunidos en dicasios corimbiformes que ramifican por debajo o arriba de la mitad del eje principal. Pedúnculos 10-80 cm de longitud (Figura 2B, D-G). Involucro campanulado o subhemisférico. Filarias externas, por lo común (6-)8-10, aunque llegan a 12 en $C$. mcvaughii y $C$. nelsonii Rob. \& Fern., oblongas o triangulares, lanceoladas, ensiformes, obovadas o truladas y acuminadas o redondeadas, de color verde oscuro, amarillento o pardo, con nervaduras múltiples, oscuras y conspicuas en su cara dorsal, gla- 




Figura 2. Arreglo de capitulescencias en el género Cosmos. A) multi-dicasio (cima compuesta) folioso ramificado a la mitad del eje principal; B) dicasio ramificado por arriba de la mitad del eje principal; C) cima compuesta asimétrica ramificada cerca de la base; D) cima compuesta foliosa corimbiforme ramificada por abajo de la mitad del eje principal; E) dicasio corimbiforme ramificado cerca de la base; F) dicasio corimbiforme ramificado cerca de la mitad del eje principal; G) escapo. Alturas para la planta completa. $\mathbf{X}=$ capítulos abortivos.

bras, adpresas, deflexas, imbricadas o libres (Figura 3A-O); filarias internas ocho, aunque siete en C. peucedanifolius o diez en $C$. concolor Sherff y $C$. diversifolius, glabras pero algunas especies tienen un mechón de pelos multicelulares en el ápice, oblongas a oblanceoladas, obovadas u ovadas, a menudo acrescentes, endurecidas en el ápice en la madurez de los capítulos, de color gris, amarillo, verde, púrpura o bien pueden ser translúcidas, con múltiples nervaduras conspicuas, hialinas (Figura 3A-O). Páleas linear-oblongas, con nervaduras oscuras o por completo translúcidas y glabras, semejando a las filarias internas. Un resumen de la variabilidad de las filarias externas e internas en Cosmos sección Discopoda se muestra en el Apéndice 2. Flores liguladas ocho, aunque pueden ser diez en $C$. concolor, $C$. diversifolius y $C$. nelsonii, ágamas; ligulas ovadas, obovadas a oblanceoladas, de color blanco (Figura 4A-F), violado (Figura 4G-X), púrpura o atropurpúreo (Figura 4AA, BB, EE, GG-MM), 3-5 nervadas y pilosas en su cara dorsal, ápice entero o tridentado. Flores del disco 21-50, aunque pueden ser 80 o más, pero en C. mcvaughii, C. nelsonii, C. pringlei B.L. Rob. y C. pseudoperfoliatus, corolas infundibuliformes o tubulares (C. nelsonii), 5-lobadas o 4-lobadas (C. pseudoperfoliatus), glabras o puberulentas en el tubo y en la garganta, de color amarillo, amarillo con lóbulos púrpura o blanco con lóbulos púrpura (Apéndice 2; Figura 4). Androceo fanerostémono, de color café o negro; anteras sagitadas, con lóbulos agudos a redondeados, apéndices ovados, caudados a redondeados, con o sin prolongación evidente del conectivo (Figura 5). Po- 


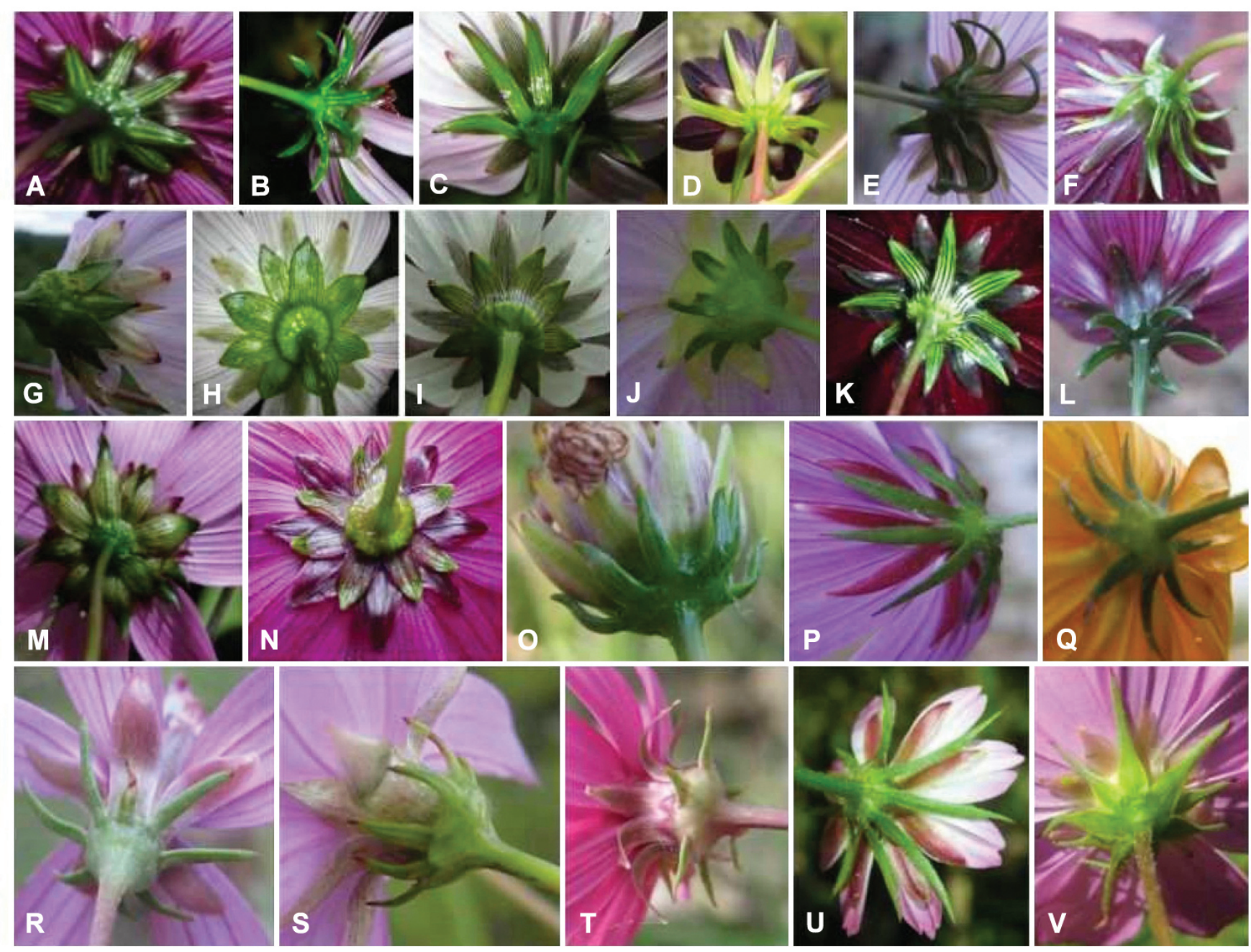

Figura 3. Variabilidad de filarias internas y externas en el género Cosmos. A) C. montanus; B) C. nitidus; C) C. schaffneri; D) C. jaliscensis; E) C. sessilis; F) C. stellatus; G) C. pringlei; H) C.diversifolius; I) C. palmeri; J) C. modestus; K) C juxtlahuacensis; L) C. scabiosoides; M) C. peucedanifolius; N) C. concolor; O) C. ramirezianus; P) C. pacificus; Q) C. sulphureus; R) C. carvifolius; S) C. ochroleucoflorus; T) C. linearifolius; U) C. caudatus; V) C. bipinnatus. Créditos: Arturo Castro-Castro (A, D-T, V); Georgina Vargas-Amado (B, C, U).

len de color amarillo. Estigma bifurcado, sus ramas seríceas en su porción media a terminal (Figura 5E-Z). La morfología de los aquenios en Cosmos sección Discopoda es útil para el reconocimiento de las especies. Aquenios lineares a fusiformes, tetragonales, erostrados y con un surco longitudinal en cada una de sus caras, rectos o falcados $(C$. mattfeldii y $C$. peucedanifolius; Figura $7 \mathrm{H}$ ), de color café claro, café obscuro o negro, glabros, escábridos en la parte distal, glabriúsculos en la porción basal o tuberculados $(C$. longipetiolatus, $C$. pseudoperfoliatus, C. sessilis y C. stellatus; Figura 7G, P, V, W). Vilano de 2-4 aristas, hasta seis (C.nelsonii, C.palmeri y $C$. pringlei) o exaristados (C. deficiens y C. mcvaughii), aristas peniciladas, retrorsamente barbeladas. Carpóforo discoide, romboide o poligonal (Figura 7). Receptáculo convexo. El número cromosómico básico en la sección es $x=12$, en su mayoría las especies son diploides, pero existen especies tetraploides, hexaploides y octoploides. Además, extremos de variación cromosómica se presentan en $C$. juxtlahuacensis ( $n$ =13) y $C$. pringlei $(n=46$; Cuadro 1$)$.

Cosmos sección Mesinenia. Sufrútices, 0.6-1.3 m de altura. Rizomas con raíces adventicias robustas a manera de un xilopodio (Figura 1E, G, H). Tallos glabros o pubescentes (Cosmos carvifolius Benth.), estriados, hexagonales o teretes $(C$. carvifolius y $C$. intercedens Sherff). Pecíolos alados y pericládicos $(C$. carvifolius, $C$. crithmifolius Kunth, $C$. intercedens y $C$. landii Sherff) o sésiles y casi perfoliados [C. linearifolius (Sch. Bip.) Hemsl. y C. ochroleucoflorus Melchert]. Hojas caulinares, coriáceas o membranáceas (C. carvifolius), enteras, lobadas o pinnatisectas, glabras o pubescentes $(C$. carvifolius y $C$. intercedens), márgenes involutos, con frecuencia con pelos rígidos y retrorsos. 


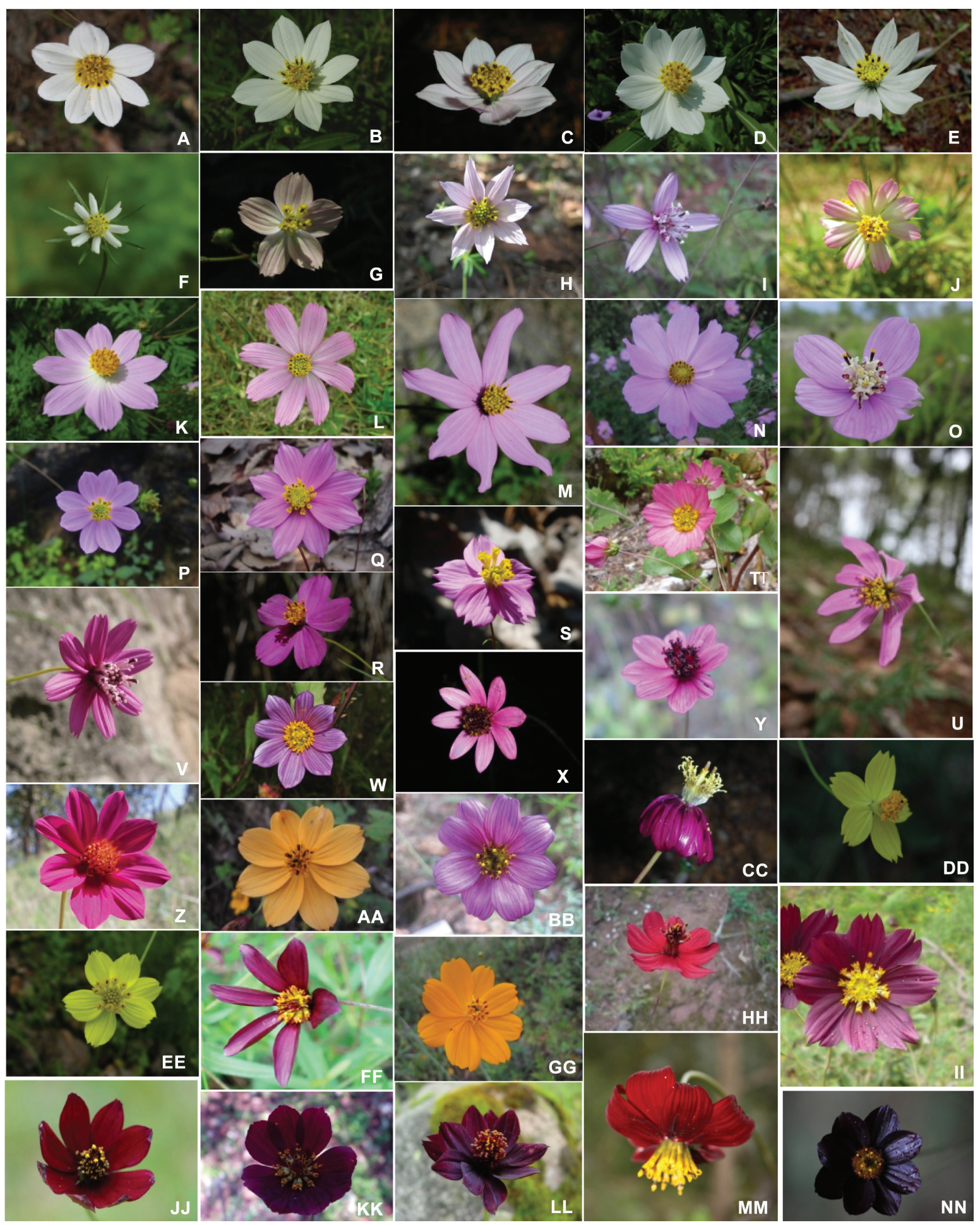

Figura 4. Variabilidad morfológica y de colores en las flores liguladas y del disco en el género Cosmos. A) C. deficiens; B) C.mcvaughii; C) C. schaffneri; D y K) C. pacificus; E) C.palmeri; F) C.parviflorus; G) C. landii var. achalconensis; H y NN) C. sessilis; I) C. carvifolius; J) C. caudatus; L) C. diversifolius; M) C.peucedanifolius; N) C. bipinnatus; O) C.ochroleucoflorus; P) C. montanus; Q) C. pseudoperfoliatus; R) C. crithmifolius; S) C. intercedens; T y II) C. stellatus; U) C. sherffi; V) C. linearifolius; W) C. montanus; X) C. nitidus; Y) C.purpureus; Z) ramirezianus; AA y GG) C. sulphureus; BB) C. scabiosoides; CC) C. juxtlahuacensis; DD y EE) C. landii var. landii; FF) C. longipetiolatus; $\mathrm{HH})$ C. mattfeldii; JJ) C. atrosanguineus; KK) C. jaliscensis; LL) C. concolor; MM) C. nelsonii. Créditos: Aarón Rodríguez (B, F, G, K, L, P, R, S, Y, DD, EE, JJ, NN); Arturo Castro-Castro (A, D, E, H, I, N, O-Q, V, Z, AA, BB, GG, II, KK, LL, TT); Francisco J. Santana-Michel (FF); Georgina Vargas-Amado (C, J, X, CC); Jesús G. González-Gallegos (HH); Pablo Carrillo-Reyes (Q); Pilar Zamora-Tavares (U, MM). 

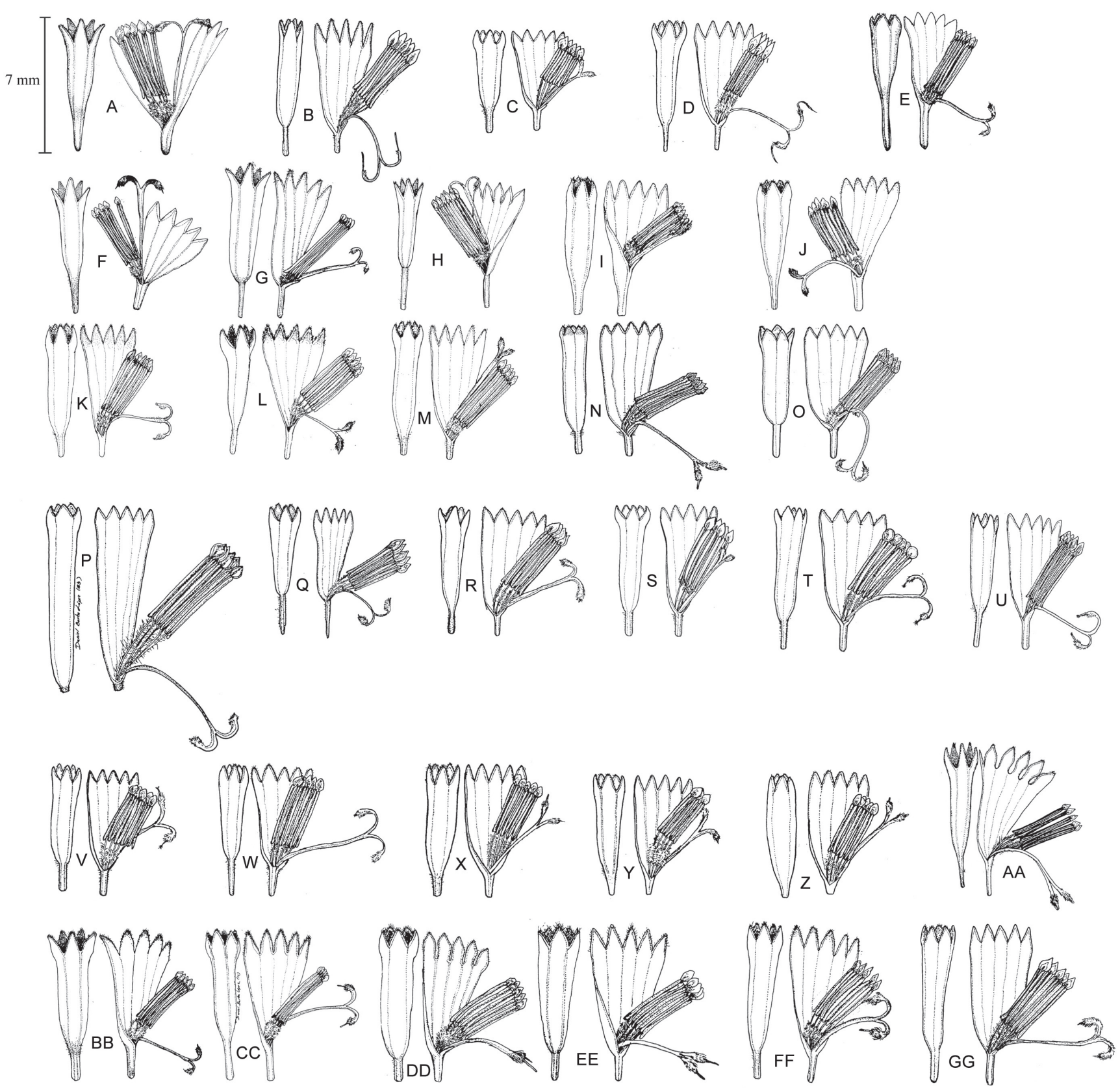

Figura 5. Variabilidad morfológica en flores del disco, androceo y gineceo en especies del género Cosmos. A-D) Cosmos sección Cosmos; E-Z) Cosmos sección Discopoda; AA-GG) Cosmos sección Mesinenia. A) C. bipinnatus (A. Rodríguez et al. 6002); B) C. pacificus (A. Rodríguez et al. 5607); C) C. parviflorus (M. Harker \& P. Carrillo-Reyes 1307); D) C. sulphureus (A. Rodríguez et al. 5652); E) C.atrosanguineus (M. Harker et al. 3881); F) C. concolor (M. Harker et al. 3976); G) C. deficiens (A. Castro-Castro et al. 2415); H) C. diversifolius (A. Rodríguez et al. 6450); I) C. jaliscensis (A. Rodríguez et al. 5913); J) C. juxtlahuacensis (A. Rodríguez et al. 5954); K) C. longipetiolatus (A. Castro-Castro \& J.L.Villa-Vázquez 2296); L) C. mattfeldii (J.G. González-Gallegos 434a); M) C. mcvaughii (M. Harker \& F.J.Rendón-Sandoval 3833); N) C. modestus (A. Rodríguez 5240); O) C. montanus (A. Castro-Castro et al. 1965); P) C. nelsonii (A. Rodríguez et al. 6525); Q) C.nitidus (A. Rodríguez \& G. Vargas-Amado 6009); R) C. palmeri (M. Harker \& A. Castro-Castro 4031); S) C. peucedanifolius (P. Carrillo-Reyes \& A. Cosacov 5941); T) C. pringlei (M. Harker et al. 3963); U) C. purpureus (A. Rodríguez \& G. Vargas-Amado 6035); V) C. scabiosoides (A. Rodríguez et al. 5662); W) C. schaffneri (A. Rodríguez \& G. Vargas-Amado 6030); X) C. sessilis (A. Castro-Castro \& L.F. Pérez-Álvarez 1859); Y) C. sherffi (A.Rodríguez et al. 6511); Z) C. stellatus (A. Castro-Castro et al. 2222); AA) C. carvifolius (M. Harker et al.3131); BB) C. crithmifolius (M. Harker et al.3348); CC) C. intercedens (A. Castro-Castro et al. 2281); DD) C. landii var. achalconensis (M. Harker et al.3912); EE) C. landii var. landii (J.A. Lomeli \& E. Sahagún 3133); FF) C. linearifolius (M. Harker \& A. Castro-Castro 4023);

GG) C. ochroleucoflorus (A. Castro-Castro et al. 1975). Ilustraciones y edición: Daniel Barba-López y Karina Castro-Castro. 

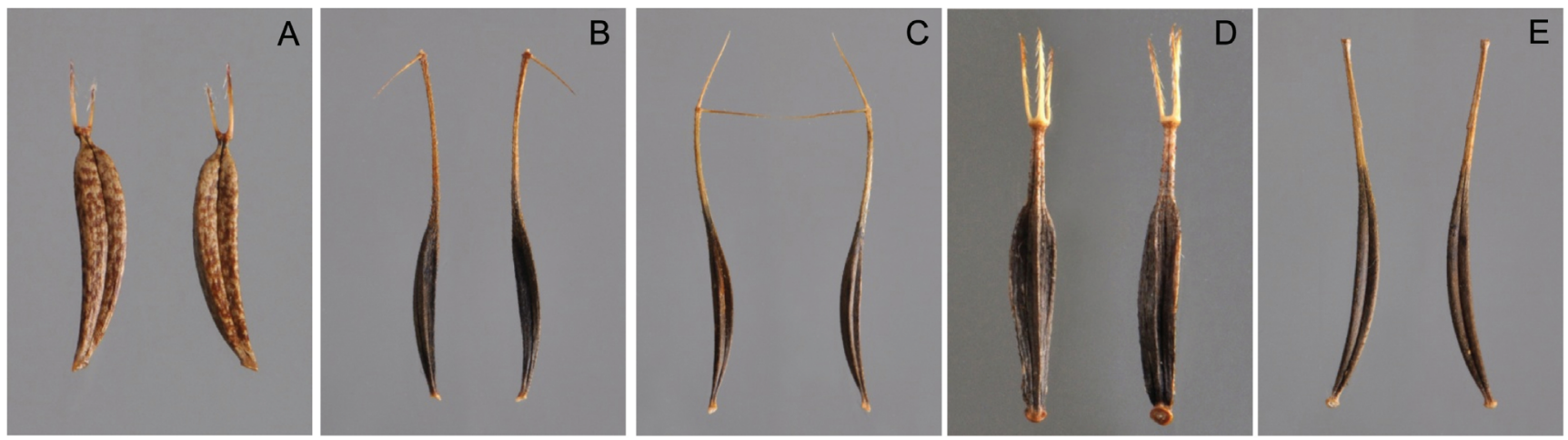

Figura 6. Variabilidad morfológica, pubescencia y vilano en aquenios del género Cosmos sección Cosmos. A) C. bipinnatus (A. Rodríguez et al. 6002); B) C. caudatus (Cabrera-Rodríguez 102); C) C. pacificus (A. Rodríguez et al. 5607); D) C. parviflorus (M. Harker \& P. Carrillo-Reyes 1307); E) C. sulphureus (A. Rodríguez et al. 5652). Ejemplares depositados en el herbario IBUG. Fotografías y edición: Susana A. de Santiago-Moreno y Karina Castro-Castro.

Segmentos y sus lóbulos lineares, filiformes o ensiformes, ápices rígidos o suavemente acuminados, con frecuencia falcados. Capítulos ordenados en un multi-dicasio folioso asimétrico que ramifica cerca de la base del eje principal (Figura 2C). El involucro es campanulado a subhemisférico. Filarias externas 4-8 (C. carvifolius), cinco (C. intercedens у $C$. landii) o 6-12 (C. crithmifolius, $C$. linearifolius y $C$. ochroleucoflorus), lineares o deltoides, rígido-acuminadas, deflexas o extendidas, no adpresas a las filarias internas, libres, de color verde, glabras (Figura 3R-T); filarias internas ocho (C. intercedens, C. landii, C. ochroleucoflorus), cinco (C. carvifolius y $C$. crithmifolius) u 8-10 (C. linearifolius), de color translúcido-grisáceo a violado, con nervaduras oscuras inconspicuas, oblongas a elípticas, agudas, naviculares, glabras pero con un mechón de pelos simples en el ápice, sus bases forman un tubo que envuelve y separa a todas las flores y páleas de las filarias externas (Figura 3R-T). Flores liguladas cinco (C. critmifolius, $C$. intercedens, $C$. landii y C. ochroleucoflorus), 5-8 (C.carvifolius) u 8-10 (C. crithmifolius y C. linearifolius), ágamas o neutras (C. crithmifolius), lígulas circulares, elípticas, lanceoladas, ovadas u oblanceoladas, de color rosado a violado (C. carvifolius, $C$. crithmifolius, $C$. intercedens, $C$. ochroleucoflorus y $C$. linearifolius), amarillo (C. landii var. landii) o amarillo pálidas (C. landii var. achalconensis Melchert), con 3-5 nervaduras pilosas en su cara dorsal (Figura 4G, I, O, R, S, V, DD, EE). Flores del disco 10-30(-60), C. crithmifolius presenta la más amplia variación, que va desde 10 hasta 60 flores, corolas tubulosas, 5-lobadas, puberulentas en el tubo y la garganta, de color amarillo (C. crithmifolius, $C$. intercedens y $C$. landii), blanco-translúcido (C. carvifolius y $C$. ochroleucoflorus) o violado (C. linearifolius; Figura 4G, I, O, R, $\mathrm{S}, \mathrm{V}, \mathrm{DD}, \mathrm{EE})$. Androceo de color café (C. crithmifolius, $C$. intercedens, C. landii y C. linearifolius) o negro (C. carvifolius y C. ochroleucoflorus; Figura 5), anteras sagitadas, con lóbulos agudos a redondeados, apéndices deltoides, con prolongación evidente del conectivo (Figura 5AA-GG). Polen de color amarillo en las especies con flores del disco de color amarillo, y blanco en las especies con flores del disco de color blanco o violado. Estigma bifurcado, ramas seríceas en su porción media a terminal (Figura 5AA-GG). Aquenios lineares a penicilados, erostrados, tetragonales, con 1 o 2 surcos longitudinales en cada una de sus caras, de color café claro u oscuro, escábridos en su porción distal o glabros (C. carvifolius), lisos (C. carvifolius, C. linearifolius y $C$. ochroleucoflorus), muricados (C. landii var. achalconensis) o tuberculados $(C$. crithmifolius y $C$. intercedens). Vilano de 2-6 aristas lineares o deltoides, retrorsamente barbeladas. Carpóforo discoide (C. carvifolius, C. crithmifolius y $C$. linearifolius), romboide (C. landii y C. ochroleucoflorus) o deltoide (C. intercedens; Figura 8). Receptáculo convexo. El número cromosómico básico en Cosmos sección Mesinenia es $x=11$, condición autapomórfica para la sección. Cosmos carvifolius y $C$. intercedens son diploides; $C$. landii, C. linearifolius y C.ochroleucoflorus son tetraploides y C. chrithmifolius es hexaploide (Cuadro 1).

\section{Discusión}

Límites morfológicos entre Cosmos y Bidens. El límite entre Cosmos y Bidens no ha sido claro, por lo que esta situación ha asimilado abundante sinonimia (p. ej. Hemsley, 1881; Sherff, 1929, 1932; Melchert, 1975, 1990a, c). Sin embargo, existen caracteres morfológicos que permiten distinguirlos. Por ejemplo, Cosmos agrupa a hierbas erectas pero algunas especies de Bidens son rastreras o trepadoras. En corte transversal, los tallos de Cosmos son teretes o hexagonales, mientras que en Bidens pueden ser teretes, tetragonales o hexagonales. En Cosmos, las hojas son opuestas. Por el contrario, en Bidens algunas especies producen hojas alternas. En Cosmos, el número de filarias oscila entre 5-8 (-10) por serie, en general son glabras y con canales resiníferos bien marcados. En contraste, en Bidens el número de filarias varía entre 4 y 22 , con frecuencia son pubescentes y 
Cuadro 1. Diversidad del género Cosmos, distribución geográfica natural y números cromosómicos. Secciones propuestas por Sherff (1932, 1955). $x=$ número cromosómico básico. $n=$ número cromosómico en condición haploide. Abreviaciones de los estados de México de acuerdo a INEGI (2013).

\begin{tabular}{|c|c|c|c|}
\hline Especies & Distribución geográfica & Distribución en México & $n$ \\
\hline \multicolumn{4}{|l|}{ Sección Cosmos Sherff $(x=12)$} \\
\hline C. bipinnatus Cav. & EUA, México y Guatemala & $\begin{array}{l}\text { Ags, Chih, Chis, Coah, DF, Dgo, Gro, Gto, } \\
\text { Hgo, Jal, Méx, Mich, Mor, Nay, NL, Oax, } \\
\text { Pue, Qro, Sin, SLP, Son, Tlax, Ver, Zac }\end{array}$ & $\begin{array}{l}n=12 \text { (Melchert, 1968, 2010a; } \\
\text { Carr et al., 1999) }\end{array}$ \\
\hline C. caudatus Kunth & $\begin{array}{l}\text { México, América Central, } \\
\text { Antillas y Sudamérica }\end{array}$ & $\begin{array}{l}\text { Chis, Oax, QRoo, SLP, Tab, } \\
\text { Tamps, Ver }\end{array}$ & $\begin{array}{l}n=24 \text { (Melchert, 1990b, } \\
\text { 2010a; Jose y Mathew, 1995) }\end{array}$ \\
\hline C. pacificus Melchert & México & Col, Gro, Jal, Méx, Mich, Sin & $n=12$ (Melchert, 1990b, 2010a) \\
\hline C. parviflorus (Jacq.) Pers. & EUA y México & $\begin{array}{l}\text { Ags, BC, Chih, DF, Dgo, Gro, Gto, Hgo, Jal, } \\
\text { Méx, Mich, Mor, Nay, NL, Oax, Pue, Qro, } \\
\text { Sin, SLP, Son, Tamps, Ver, Zac }\end{array}$ & $\begin{array}{l}n=12 \text { (Melchert 1968, 2010a; } \\
\text { Keil y Stuessy, 1975; Carr } \\
\text { et al., 1999) }\end{array}$ \\
\hline C. sulphureus Cav. & México, América Central & $\begin{array}{l}\text { Ags, BC, Chis, Col, Dgo, Gro, Gto, Jal, Méx, } \\
\text { Mich, Mor, Nay, NL, Oax, Pue, Qro, QRoo, } \\
\text { Sin, SLP, Son, Ver, Yuc, Zac }\end{array}$ & $\begin{array}{l}n=12 \text { (Melchert, 1968, } \\
\text { 2010a) }\end{array}$ \\
\hline \multicolumn{4}{|c|}{ Sección Discopoda (DC.) Sherff $(x=12)$} \\
\hline $\begin{array}{l}\text { C. atrosanguineus (Hook.) } \\
\text { A. Voss }\end{array}$ & México & Gto, Hgo, Qro, SLP & $\begin{array}{l}n=24 \text { (Lawrence, 1929; Castro- } \\
\text { Castro et al., datos sin publicar) }\end{array}$ \\
\hline C. concolor Sherff & México & Dgo, Zac & $n=36$ (Melchert, 1968) \\
\hline C. deficiens Melchert & México & Jal & $n=12($ Melchert, 2010a $)$ \\
\hline $\begin{array}{l}\text { C. diversifolius Otto ex } \\
\text { Knowles \& Westc. }\end{array}$ & México y Guatemala & $\begin{array}{l}\text { Chis, DF, Gto, Hgo, Méx, Mich, Mor, Oax, } \\
\text { Pue, Qro, SLP, Tamps, Tlax, Ver }\end{array}$ & $\begin{array}{l}n=12,24 \text { (Melchert, 1968, } \\
\text { 2010a; Turner et al., 1961, 1962) }\end{array}$ \\
\hline C. jaliscensis Sherff & México & Jal & $n=24,36$ (Melchert 1968, 2010a) \\
\hline $\begin{array}{l}\text { C. juxtlahuacensis Panero } \\
\& \text { Villaseñor }\end{array}$ & México & Oax & $n=13($ Strother y Panero, 2001) \\
\hline C. longipetiolatus Melchert & México & Jal & Sin dato \\
\hline C. mattfeldii Sherff & México & Gro & Sin dato \\
\hline C. mcvaughii Sherff & México & Jal & $n=12$ (Melchert, 1968) \\
\hline C. modestus Sherff & México & Méx & $n=12$ (Melchert, 2010a) \\
\hline C. montanus Sherff & México & Dgo, Jal, Nay, Zac & $n=24$ (Melchert, 1968) \\
\hline C. nelsonii Rob. \& Fern. & México & Oax & $\begin{array}{l}n=24 \text { (Castro-Castro et al., datos } \\
\text { sin publicar) }\end{array}$ \\
\hline C. nitidus Paray & México & Méx & $\begin{array}{l}n=12 \text { (Castro-Castro et al., datos } \\
\text { sin publicar) }\end{array}$ \\
\hline C. palmeri B. L. Rob. & México & Ags, Chih, Dgo, Gto, Jal, SLP, Zac & $n=24($ Melchert, 1968, 2010a) \\
\hline C. peucedanifolius Wedd. & Argentina, Bolivia y Perú & & $n=12($ Robinson et al., 1981) \\
\hline C. pringlei B. L. Rob. & México & Chih, Dgo, Gto, Nay & $n=46,48$ (Melchert, 2010a) \\
\hline $\begin{array}{l}\text { C. pseudoperfoliatus Art. } \\
\text { Castro, Harker \& Aaron Rodr. }\end{array}$ & México & Jal & $\begin{array}{l}n=24 \text { (Castro-Castro et al., datos } \\
\text { sin publicar) }\end{array}$ \\
\hline $\begin{array}{l}\text { C. purpureus (DC.) Benth } \\
\text { \& Hook.f. ex Hemsl. }\end{array}$ & México & Gro, Méx, Mor, Oax & $\begin{array}{l}n=12,24 \text { (Melchert, 1968, } \\
\text { 2010a) }\end{array}$ \\
\hline
\end{tabular}


Cuadro 1. Continuación

\begin{tabular}{|c|c|c|c|}
\hline Especies & Distribución geográfica & Distribución en México & $n$ \\
\hline $\begin{array}{l}\text { C. ramirezianus Art. Castro, } \\
\text { Harker \& Aaron Rodr. }\end{array}$ & México & Jal & $\begin{array}{l}n=12 \text { (Castro-Castro et al., } \\
\text { datos sin publicar) }\end{array}$ \\
\hline C. scabiosoides Kunth & México & $\begin{array}{l}\text { Chis, DF, Dgo, Jal, Méx, Mich, Mor, Nay, } \\
\text { Pue, Tlax, Ver, Zac }\end{array}$ & $\begin{array}{l}n=12,24 \text { (Melchert, 1968, } \\
\text { 2010a) }\end{array}$ \\
\hline C. schaffneri Sherff & México & Gro, Méx & $n=12($ Melchert, 1968) \\
\hline C. sessilis Sherff & México & Jal & $n=12($ Melchert, 1967) \\
\hline C. sherffii Melchert & México & Oax & $n=12($ Melchert, 1967) \\
\hline C. stellatus Sherff & México & Jal, Mich & $n=12($ Melchert, 1990a, 2010a) \\
\hline \multicolumn{4}{|l|}{ Sección Mesinenia Sherff $(x=11)$} \\
\hline C. carvifolius Benth. & México & Dgo, Jal, Mich, Nay, Sin & $n=11($ Melchert, 1968, 2010a) \\
\hline C. crithmifolius Kunth & México y América Central & $\begin{array}{l}\text { Ags, Chis, DF, Dgo, Gro, Gto, Jal, Méx, } \\
\text { Mich, Mor, Nay, Oax, Pue, Qro, Sin, SLP, } \\
\text { Tamps, Ver, Zac }\end{array}$ & $n=33$ (Melchert, 1968, 2010a) \\
\hline C. intercedens Sherff & México & Jal, Nay & $n=11$ (Melchert, 1968, 2010a) \\
\hline C. landii Sherff var. landii & México & Jal & $n=22($ Melchert, 1968, 2010a) \\
\hline $\begin{array}{l}\text { C. landii Sherff var. } \\
\text { achalconensis Melchert }\end{array}$ & México & Jal & $n=22($ Melchert, 1968, 2010a) \\
\hline $\begin{array}{l}\text { C. linearifolius (Sch. Bip.) } \\
\text { Hemsl. }\end{array}$ & México & Chih, Dgo, Jal, Mich, Nay & $n=22($ Melchert, 1968) \\
\hline $\begin{array}{l}\text { C. linearifolius (Sch. Bip.) } \\
\text { Hemsl. var. maysilesii Sherff }\end{array}$ & México & Dgo & $n=22($ Melchert, 1968) \\
\hline $\begin{array}{l}\text { C. linearifolius (Sch. Bip.) } \\
\text { Hemsl. var. magnifolius Sherff }\end{array}$ & México & Chih & $n=22$ (Melchert, 1968) \\
\hline C. ochroleucoflorus Melchert & México & Dgo, Jal, Nay & $n=22$ (Melchert, 1968, 2010a) \\
\hline
\end{tabular}

los canales resiníferos están ausentes o son inconspicuos. En Cosmos los capítulos son heterógamos, y con frecuencia son homógamos en Bidens. Las flores liguladas son ágamas o neutras en Cosmos y fértiles en algunas especies de Bidens. En Cosmos los filamentos son pubescentes en sus partes medias pero glabros en el resto de las Coreopsideae, incluido Bidens. Por otro lado, los aquenios en Cosmos son tetragonales, con uno o dos surcos longitudinales en cada una de sus caras y con vilano de aristas retrorso barbeladas. En cambio, en Bidens, los aquenios son 3 o 4-gonales o dorsalmente aplanados, con 2-4 surcos por cara y con vilano de aristas antrorso o retrorso barbeladas. Aún más, a diferencia de Cosmos, en algunas especies de Bidens se desarrollan aquenios alados.

Complejos de especies en Cosmos sección Discopoda. Cosmos es morfológicamente muy diverso y citológicamente complejo. Para su identificación se requiere el análisis de tantos caracteres como sea posible, incluída la distribución geográfica. A partir de la experiencia obtenida de este análisis, es pertinente hacer recomendaciones sobre la recolección de ejemplares botánicos, con el fin de que el proceso de identificación sea lo más fácil posible. En primer lugar y en la medida de lo posible, se debe recolectar toda la planta; de lo contrario, se sugiere hacer observaciones sobre el hábito de crecimiento y tipo de raíz. También es importante indicar el número de filarias por serie y el color de las flores del disco. Es muy recomendable incluir aquenios y capítulos adicionales que permitan examinar todos sus lados y preparar disecciones.

Existen complejos de especies en donde los límites morfológicos no son claros. Un caso es la delimitación entre Cosmos scabiosoides, C. mattfeldii y C.jaliscensis. La morfología vegetativa de estas tres especies es confusa y parece representar una variación clinal a lo largo de una amplia área geográfica (Cuadro 1). Caracteres útiles en su delimitación son las dimensiones, pubescencia y segmentación de las hojas, forma y tamaño de las dos series de filarias y la 

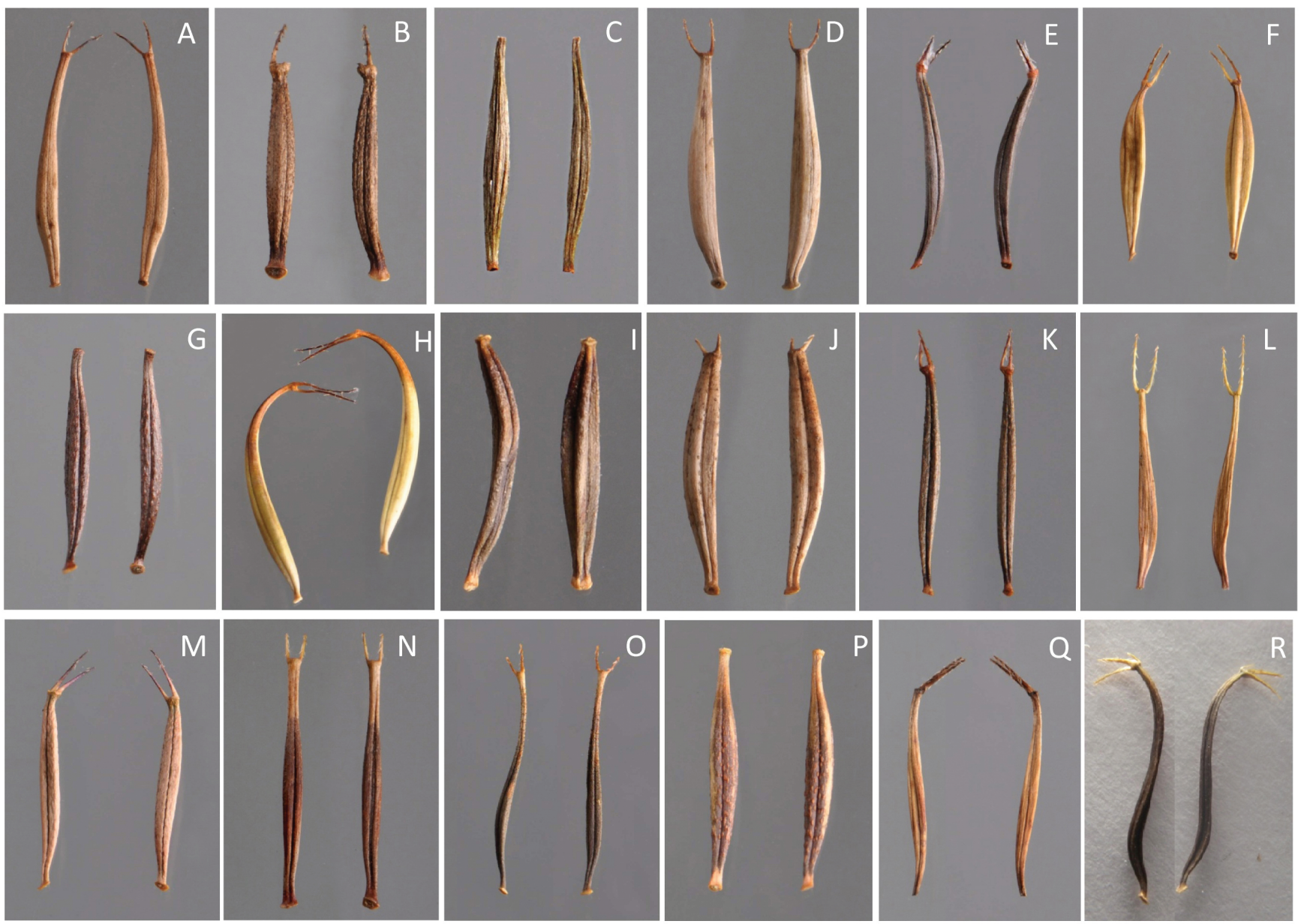

$\mathrm{P}$


Figura 7. Variabilidad morfológica, pubescencia y vilano en aquenios del género Cosmos sección Discopoda. A) C. atrosanguineus (M. Harker et al. 3881); B) C. concolor (M. Harker et al. 3976); C) C. deficiens (A. Castro-Castro et al. 2415); D) C. diversifolius (A. Rodríguez et al. 6450); E) C. jaliscensis (A. Rodríguez et al. 5913); F) C. juxtlahuacensis (A. Rodríguez et al. 5954); G) C. longipetiolatus (A. Castro-Castro \& J.L. Villa-Vázquez 2296); H) C. mattfeldii (J.G. González-Gallegos 434a); I) C. mcvaughii (M. Harker \& F.J. Rendón-Sandoval 3833); J) C. modestus (A. Rodríguez 5240); K) C. montanus (A. Castro-Castro et al. 1965); L) C. nelsonii (A. Rodríguez et al.6525); M) C. nitidus (A.Rodríguez \& G. Vargas-Amado 6009); N) C.palmeri (M. Harker \& A. Castro-Castro 4031); O) C.pringlei (M. Harker et al.3963); P) C. pseudoperfoliatus (A. Castro-Castro \& A. Rodríguez 1979); Q) C. purpureus (A. Rodríguez \& G. Vargas-Amado 6035); R) C. peucedanifolius (L.J. Novara 8607, SI); S) C. ramirezianus (A. Castro-Castro \& L.M. González-Villarreal 2295); T) C. scabiosoides (A. Rodríguez et al. 5662); U) C. schaffneri (A. Rodríguez \& G. Vargas-Amado 6030); V) C. sessilis (A. Castro-Castro \& L.F. Pérez-Álvarez, 1859); W) C. stellatus (A. Castro-Castro et al.2222). Ejemplares depositados en el herbario IBUG, excepto C.peucedanifolius. Fotografías y edición: Susana A. de Santiago-Moreno y Karina Castro-Castro. 


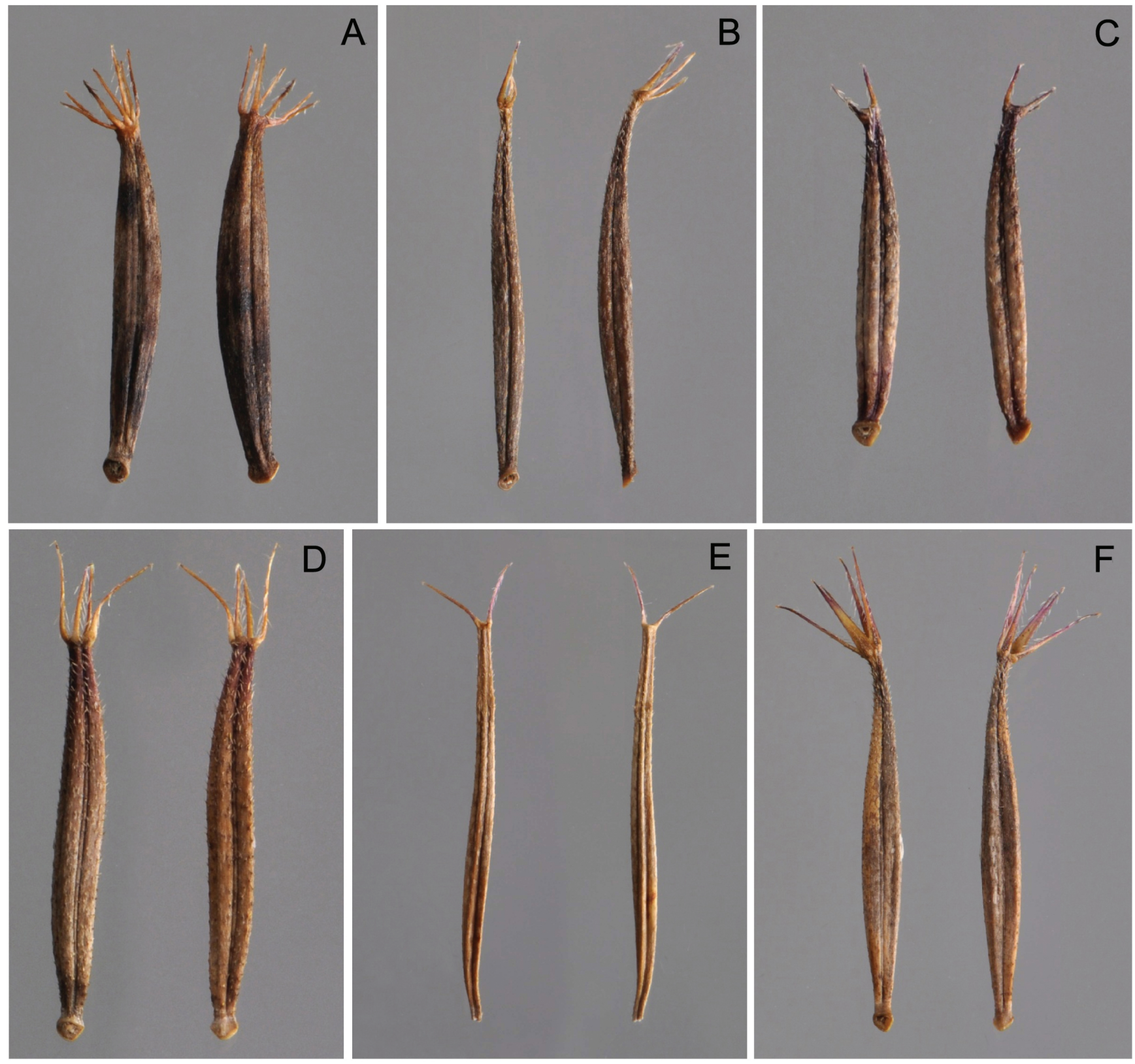

Figura 8. Variabilidad morfológica, pubescencia y vilano en aquenios del género Cosmos sección Mesinenia. A) C.carvifolius (M. Harker et al. 3131); B) C. crithmifolius (M. Harker et al.3348); C) C. intercedens (A. Castro-Castro et al. 2281); D) C. landii var. achalconensis (M. Harker et al. 3912); E) C. linearifolius (M. Harker \& A. Castro-Castro 4023); F) C. ochroleucoflorus (A. Castro-Castro et al. 1944). Ejemplares depositados en el herbario IBUG. Fotografías y edición: Susana A. de Santiago-Moreno y Karina Castro-Castro.

morfología de los aquenios (Apéndice 2; Figuras 2, 3, 4, 7). Otro aspecto que resulta de utilidad en el reconocimiento de estos taxa es su distribución geográfica. Cosmos jaliscensis sólo se conoce del oeste de Jalisco en la Faja Volcánica Transmexicana, C. mattfeldii crece en una porción estrecha de la Sierra Madre del Sur, en Guerrero, y C. scabiosoides se distribuye en el sur de la Sierra Madre Occidental y a lo largo de la Faja Volcánica Transmexicana (Vargas-Amado et al., 2013; Cuadro 1).
Otro caso es el complejo Cosmos sessilis y $C$. stellatus. Ambas especies tienen una distribución restringuida al occidente de México, en la zona de transición entre la Faja Volcánica Transmexicana y la Sierra Madre del Sur. De acuerdo a Sherff (1964), C. sessilis produce un sólo tallo mientras que $C$. stellatus ramifica en 2 o 3 tallos. En $C$. sessilis las hojas son 3-7 lobadas y de lóbulos lanceolados y enteros, mientras que en C. stellatus las hojas son 5-7 lobadas y de lóbulos lineares y pinnatisectos. Sherff (1964) también 
señaló que $C$. sessilis tiene capítulos discoides y aquenios exaristados. Mientras que en $C$. stellatus los capítulos son radiados y los aquenios biaristados. Sin embargo, estas diferencias son aparentes y dependen del estado fenológico en que se colectan. Ambas especies producen capítulos radiados pero las flores liguladas son caedizas. Aún más, las formas descritas por Sherff (1964) pueden ser localizadas en simpatría en las sierras de Juanacatlán, Quila y San Sebastián del Oeste, Jalisco, México (A. Castro-Castro y L.F. Pérez 1859; A. Rodríguez et al. 5916, 5922; J.A. Pérez de la Rosa 2031; J.G. González-Gallegos y R. Guerrero 1100; M. Harker et al. 3122, 3155, 3362, 4005; R. Ramírez-Delgadillo y A. Langle 6207; R. Ramirez-Delgadillo et al. 7689; ejemplares depositados en IBUG).

En esta misma sección, es posible que el par integrado por Cosmos palmeri y C. pringlei represente otro caso de variación clinal de una sola especie. Robinson (1909) señaló, en los protólogos de ambas especies, una serie de caracteres que cuantitativamente se traslapan o son continuos. Los individuos analizados en el presente estudio muestran esta misma situación, observándose una diferenciación local, correlacionada con las condiciones edáficas, de altitud y de clima. Esta correlación también existe cuando se analiza la distribución geográfica y los niveles de ploidía de las especies. De acuerdo a Vargas-Amado et al. (2013), C. pringlei se desarrolla con mayor frecuencia en la porción norte de la Sierra Madre Occidental, en donde las poblaciones analizadas por Melchert (2010a) son octoploides (Cuadro 1). Mientras que $C$. palmeri mantiene una distribución más amplia, compartiendo espacios con $C$. pringlei, pero extendiéndose hacia el sur del mismo sistema de montañas y con poblaciones tetraploides (Cuadro 1).

Cosmos nitidus y $C$. purpureus constituyen otro par de especies difíciles de distinguir. No es posible diferenciarlas morfológicamente si se tiene en cuenta las hojas, filarias y flores liguladas (Cuadro 1). Sólo se pueden distinguir si se tienen en cuenta la longitud de los internodos, la segmentación y pubescencia de las hojas y, la dimensión y márgenes de los folíolos (ver clave dicotómica). Ambas crecen en simpatría en el sur de México. Cosmos nitidus se restringe al municipio de Sultepec en el Estado de México y C.purpureus se extiende además, a los estados de Guerrero y Morelos (Vargas-Amado et al., 2013; Cuadro 1)

Un último complejo dentro Cosmos sección Discopoda es el formado por C. diversifolius y C.peucedanifolius. Entre ambas especies, la labilidad de los caracteres foliares es similar y amplia (Apéndice 2). Los capítulos son también similares, aunque la forma, color y tamaño de las filarias es distinta (Apéndice 2). Los aquenios en $C$. diversifolius son fusiformes, tetragonales, de color café claro y 2-6 aristados, mientras que en $C$. peucedanifolius son fusiformes, ligeramente aplanados, falcados, de color café oscuro y 2-3 aristados (Figura 7). En cuanto a su distribución, C. diversifolius es una especie distribuida del noreste de México a
Guatemala, mientras que $C$. peucedanifolius se restringe al norte de Argentina, oeste de Bolivia y sur de Perú (VargasAmado et al., 2013).

Complejos de especies en Cosmos sección Mesinenia. Dentro de Cosmos sección Mesinenia, los límites entre C.crithmifolius, $C$. intercedens y $C$. landii son difíciles de establecer. Sherff (1964) separó a $C$. intercedens de $C$. crithmifolius por tener segmentos de las hojas falcados y de $1.5-3.5 \mathrm{~cm}$ de longitud, y pecíolos alados de $1.0 \mathrm{~cm}$ de longitud. McVaugh (1984) consideró a C. intercedens y C. landii tan sólo como variantes geográficas de $C$. crithmifolius, restringidas a las barrancas de las cuencas de los ríos Santiago y Ameca en el centro de Jalisco y sur de Nayarit, México. Por su lado, Melchert (2010a, b) reconoció a C. landii y C. crithmifolius, con base en los niveles de ploidía, como variantes tetraploide y hexaploide del diploide $C$. intercedens, respectivamente. Aunque los límites morfológicos entre estos taxa son complejos, caracteres como las dimensiones y formas foliares, el número y color de las flores liguladas y del disco, morfología de los aquenios y la distribución geográfica, son útiles en su reconocimiento (Cuadro 1; Figuras 5, 6, 9; ver clave dicotómica).

Correlación entre morfología y números cromosómicos en Cosmos. En Angiospermas, la aneuploidía y la poliploidía son frecuentes y han jugado un papel importante en su diversificación (Jiao et al., 2011). Los diferentes niveles de ploidía observados en Cosmos se han explicado como eventos de aneuploidía y poliploidía (Melchert, 1968). Como muestra, $42 \%$ de los taxa reconocidos y de los cuales se conocen sus números cromosómicos son poliploides. El número básico de cromosomas es $x=11,12$ y 13 , con una serie gamética amplia ( $n=11,22,33 ; n=12,24,48$, Cuadro 1$)$.

En Cosmos sección Cosmos, C. bipinnatus, C. pacificus, C. parviflorus y $C$. sulphureus son diploides $(2 n=2 x=24)$. En cambio, $C$. caudatus es tetraploide $(2 n=4 x=48)$. Por su morfología general, $C$. bipinnatus y $C$. parviflorus representan un subconjunto distinto al grupo conformado por $C$. caudatus, $C$. pacificus y $C$. sulphureus, y no existe una correlación entre niveles cromosómicos y la morfología de las especies. Por su parte, en Cosmos sección Mesinenia, $C$. carvifolius y $C$. intercedens son diploides; $C$. landii, $C$. linearifolius y $C$. ochroleucoflorus son tetraploides y, $C$. crithmifolius es hexaploide. Cosmos carvifolius $(n=11)$, $C$. intercedens $(n=11)$ y $C$. landii $(n=22)$ representan una serie morfológicamente distinta al complejo poliploide integrado por $C$. crithmifolius $(n=33)$, C. linearifolius $(n=22)$ y $C$. ochroleucoflorus $(n=22)$. Aunque Melchert (2010a) encontró poblaciones diploides de $C$. linearifolius $(n=11)$, en ambas secciones la poliploidía explica la diversidad cromosómica.

En contraste, la variación cromosómica en Cosmos sección Discopoda implica otros procesos. En esta sección se 
distinguen dos grupos de especies morfológicamente similares y poliploides. El primer grupo está representado por los tetraploides $C$. atrosanguineus, $C$. concolor, $C$. montanus, C. nelsonii y C.palmeri $(2 n=4 x=48)$. En este mismo complejo, en $C$.jaliscensis hay poblaciones tetraploides y hexaploides $(2 n=4 x=48 ; 2 n=6 x=72)$. De forma análoga, C. purpureus y $C$. scabiosoides producen poblaciones diploides y tetraploides $(2 n=2 x=24 ; 2 n=4 x=48)$. Asî mismo, $C$. pringlei representa un caso donde la poliploidía y la aneuploidía explican su variación cromosómica. En esta especie se han registrado dos tipos de poblaciones octoploides. En la primera $2 n=8 x=96$. La segunda requiere además una modificación a la serie poliploide, pues $2 n=8 x=92$, fenómeno denominado por Darlington (1956) y Grant (1989) como reducción de la poliploidía (Cuadro 1). En apariencia morfológica, este primer grupo es diferente a un segundo complejo de especies en su mayoría diploides y formado por $C$. deficiens, C. mcvaughii, C. modestus, C. nitidus, $C$. peucedanifolius, C. ramirezianus, $C$. schaffnerii, C. sessilis, C. sherffii y C. stellatus $(2 n=2 x=24$; Cuadro 1$)$. En este grupo, una excepción es $C$. diversifolius, que tiene poblaciones diploides y tetraploides $(2 n=2 x=24 ; 2 n=4 x=48)$. Otra excepción es el aneuploide $C$. juxtlahuacensis $(2 n=$ $2 x=26$ ). Estos hechos resultan de interés en un contexto filogenético, bajo el cual se podría plantear la hipótesis de un origen común de las especies con niveles de ploidía compartido; o por el contrario, la repetición de distintas series de ploidía por eventos independientes.

En Cosmos, la hibridación es otro fenómeno común. Con frecuencia se encuentran individuos que representan híbridos naturales. Por ejemplo, en Cosmos sección Mesinenia han sido identificados híbridos entre C. carvifolius y C. linearifolius (Melchert, 1968), y otros examinados durante la revisión de herbarios del presente trabajo ( $N$. Carman et al. 65b, MEXU, tres ejemplares). Estos individuos resultan interesantes en un contexto biogeográfico, puesto que se encuentran justo en las zonas de contacto de la distribución natural de estas dos especies (Vargas-Amado et al., 2013). La hibridación entre estas especies se puede inferir cuando se analizan distintos caracteres morfológicos. Los individuos híbridos presentan hojas simples y capítulos con ocho flores liguladas como en $C$. linearifolius, pero los segmentos de las hojas son membranáceos y filiformes como en $C$. carvifolius. Además, las flores del disco son translúcidas y similares a $C$. carvifolius, pero su cantidad en cada capítulo es semejante a $C$. linearifolius.

Un escenario similar ocurre entre Cosmos crithmifolius, C. intercedens y C.carvifolius. Durante el trabajo de campo del presente estudio, se encontraron poblaciones simpátricas de estos tres taxa en el municipio de Ayutla, Jalisco, México. Allí, las formas de morfología intermedia son comunes ( $M$. Harker \& A. Castro-Castro 4199, 4200, IBUG.). Otro caso fue documentado por Melchert (1968), entre C. linearifolius у C. ochroleucoflorus (D.E. Breedlove 4251, TEX). Asimis- mo, el aislamiento reproductivo entre especies de Cosmos sección Cosmos no es completo. La hibridación entre $C$. pacificus y $C$. sulphureus es frecuente en la vertiente del Pacífico de Jalisco, México, en donde es común localizar poblaciones en simpatría con individuos de morfología intermedia (J.G. González-Gallegos y D. Juárez, 1143, IBUG, IEB, MEXU).

Por último, en Cosmos existe una correlación entre hábitos de crecimiento y números cromosómicos. Las especies perennes tienen con mayor frecuencia niveles de ploidía más elevados que las anuales (Cuadro 1). Por ejemplo, el 78\% de las especies sufrútices de Cosmos sección Mesinenia son poliploides. Aún más, cuando se comparan las hierbas perennes y anuales, la tendencia a la poliploidía es mayor en las perennes (Cuadro 1). Este hecho concuerda con lo observado por Müntzing (1936) en los géneros Helianthus, Zea y Sorghum y, por Stebbins (1938) en 220 géneros de dicotiledóneas.

Correlación entre números cromosómicos y distribución geográfica en Cosmos. La poliploidía es un proceso evolutivo importante (Soltis y Soltis, 1999; Wood et al., 2009). Produce variación genética y facilita la colonización de nuevos y diferentes hábitats (Soltis et al., 2009). Como consecuencia, se espera que los poliploides tengan una distribución geográfica más amplia en comparación con sus congéneres diploides (Grant, 1989). En Cosmos, las observaciones en este sentido son contradictorias.

En el grupo de las hierbas anuales, Cosmos caudatus es tetraploide y tiene la distribución geográfica más amplia. Con una distribución similar, pero menor, se encuentra $C$. sulphureus, un diploide. Las otras especies diploides del grupo, C. bipinnatus, $C$. pacificus y $C$. parviflorus, tienen rangos de distribución menores (Vargas et al., 2013).

De forma similar, en las especies sufrútices, el hexaploide $C$. crithmifolius está ampliamente distribuido en México y se extiende hasta Guatemala, Honduras, Nicaragua y Costa Rica (Vargas-Amado et al., 2013; Cuadro 1). A su vez, los tetraploides $C$. landii, C. linearifolius y $C$. ochroleucoflorus tienen una distribución geográfica restringida en la Sierra Madre Occidental en México. Sin embargo, la distribución geográfica del diploide $C$. carvifolius es más amplia que la de sus congéneres tetraploides y se extiende en la Sierra Madre Occidental y la Faja Volcánica Transmexicana.

Cosmos sección Discopoda requiere un análisis por si sólo. La sección agrupa a 24 especies, diez son diploides y cuentan con una distribución geográfica restringida las siguientes especies: $C$. deficiens, $C$. juxtlahuacensis, $C$. mcvaughii, C. modestus, C. nitidus, C. ramirezianus, $C$. schaffneri, $C$. sessilis, $C$. sherffii y $C$. stellatus. La excepción entre los diploides es $C$. peucedanifolius, cuya distribución se extiende a través de Los Andes en Perú, Bolivia y Argentina. Cosmos diversifoloius y C. scabiosoides tienen poblaciones diploides y tetraploides con una distribución 
geográfica muy grande en México (Vargas-Amado et al., 2013; Cuadro 1). Ambos taxa ocupan rangos elevacionales amplios sobre hábitats diversos, comportamiento que confirma el fenómeno denominado por Grant (1989) como homeostasis fisiológica aumentada y que apoyan el principio de heterosis. En contraste, $C$. purpureus tiene la misma condición de ploidía, pero su rango geográfico es reducido. Cosmos atrosanguineus, C. montanus, C. nelsonii, $C$. palmeri y $C$. pseudoperfoliatus son tetraploides y microendémicos con rangos elevacionales estrechos y con requerimientos de hábitat particulares. Cosmos jaliscensis agrupa poblaciones tetraploides y hexaploides; sin embargo, es una especie endémica de la parte oeste de Jalisco, México. Otro caso interesante es $C$. concolor, un hexaploide endémico del sur de la Sierra Madre Occidental. Por último, se tiene el caso de $C$. pringlei, un octoploide restringido al norte de la Sierra Madre Occidental (Vargas-Amado et al., 2013; Cuadro 1). En conclusión, las hierbas perennes no muestran una relación directa entre los niveles de ploidía y la distribución geográfica. Inferencias acerca de la evolución cromosómica podrían ser abordadas a la luz del conocimiento de la genética de poblaciones, las relaciones filogenéticas y el análisis de procesos de hibridación e introgresión en Cosmos.

\section{Agradecimientos}

Agradecemos al Consejo Nacional de Ciencia y Tecnología (CONACyT) por el financiamiento otorgado al proyecto 80200 y las becas concedidas a GVA (228901) y ACC (229039). Gracias a la Universidad de Guadalajara por el apoyo financiero otorgado a ACC (V/2010/316) y a la organización Idea Wild por el equipamiento concedido a ACC. Asimismo, se agradece al personal de los herbarios B, BAA, CIIDIR, ENCB, G, GUADA, HCIB, HUMO, IBUG, IEB, JUA, LIL, LP, LPAG, LPB, LPC, MCNS, MEXU, MO, MOL, NY, TEX, UAGC, USZ, XAL y ZEA por las facilidades cedidas. Un agradecimiento especial a Tom Wendt de la Universidad de Texas por la digitalización de ejemplares de herbario. ACC agradece de manera especial a Estrella Urtubey, Mónica Ihasz y Susana Freire del Instituto de Botánica Darwinion; a Marilú Parrado, Nora Muruaga y Luis Moreno de la Fundación Miguel Lillo; a Thamara Chuviru y Roxana Ledezma del Museo de Historia Natural Noel Kempff y; a Olga Martínez y Janet Chambi de la Universidad Nacional de Salta, por la confianza, hospitalidad y asesoría conferida. Gracias a Ana Villegas, Guadalupe Munguía Lino, Judith Ochoa, Luz María González Villarreal, Pilar Zamora Tavares, Virginia Ramírez Cruz, Alfredo Frías Castro, Elián Guerrero, Ernesto De Castro Arce, Jesús González Gallegos, José Luis Villa Vázquez y Pablo Carrillo Reyes por su asistencia durante el trabajo de campo y la autorización para el uso de fotografías. Los atinados comentarios y sugerencias de tres revisores mejoraron el manuscrito sustancialmente. Por último, agradecemos a Susana A. de Santiago Moreno por la fotografía y a Daniel Barba López por su apoyo en la elaboración de ilustraciones.

\section{Literatura citada}

Carr G.D., King R.M., Powell A.M. y Robinson H. 1999. Cromosome numbers in Compositae. XVIII. American Journal of Botany 86:1003-1013.

Castro-Castro A., Harker M., Vargas-Amado G. y Rodríguez A. 2013. Two new species of Cosmos section Discopoda (Coreopsideae: Asteraceae) from Jalisco, Mexico. Phytotaxa 146:35-49.

Crawford D.J. 1982. Chromosome numbers and taxonomic notes for Mexican Coreopsis, sections Electra and Pseudoagarista (Compositae: Heliantheae). Brittonia 34:384-387.

Crawford D.J. y Stuessy T.F. 1981. The taxonomic significance of anthochlors in the subtribe Coreopsidinae (Compositae, Heliantheae). American Journal of Botany 68:107-117.

Crawford D.J., Tadesse M., Mort M.E., Kimball R.T. y Randle C.P. 2009. Coreopsideae. En: Funk V.A., Susanna A., Stuessy T.F. y Bayer R.J. Eds. Systematics, Evolution and Biogeography of Compositae, pp. 713-730, International Association for Plant Taxonomy, Universidad de Viena, Viena.

Darlington C.D. 1956. Natural populations and the breakdown of classical genetics. Proceedings of the Royal Society of London, Series B, Biological Sciences 920:350-364.

De Candolle A.P. 1836. Prodromus Sistematis Naturalis Regni Vegetabilis. Pars Quinta. Paris.

Font Quer P. 1953. Diccionario de Botánica. 2a ed. Península. Barcelona.

Grant V. 1989. Especiación Vegetal. Limusa. México, D.F.

Greenman J. M. 1904. Diagnoses and synonymy of Mexican and Central American Spermatophytes. Proceedings of the American Academy of Arts and Sciences 40:28-52.

Harris J.G. y Harris M.W. 1994. Plant Identification Terminology. An Illustratated Glossary. Springer Lake Publishing, Payson.

Hemsley W.B. 1881. Botanica. En: Godman F.D. y Salvin O. Eds. Biologia Centrali-Americana; or Contributions to the Knowledge of the Fauna and Flora of Mexico and Central America, pp. 198-199, R.H Porter y Dulao \& CO., Londres.

Hind N. 2005. Cosmos peucedanifolius: Compositae. Curtis's Botanical Magazine 22:161-168.

Hind N. y Fay M.F. 2003. Cosmos atrosanguineus: Compositae. Curtis's Botanical Magazine 20:40-48.

INEGI. Instituto Nacional de Estadística y Geografía. 2013. Abreviaturas de las entidades federativas, México. <http://www.inegi.org.mx/> (consultado 8 abril 2013).

Jiao Y., Wickett N.J, Ayyampalayam S., Chanderbali A.S., Landherr L., Ralph P.E., Tomsho L.P., Hu Y., Liang H., Soltis P.S., Soltis D.E., Clifton S.W., Schlarbaum S.E., Schuster S.C., Ma H., Leebens-Mack J., de Pamphilis C.W. 2011. Ancestral polyploidy in seed plants and angiosperms. Nature 473:97-100.

Jose J.C. y Mathew P.M. 1995. Chromosome numbers in the South Indian Heliantheae (Compositae). Compositae Newsletter 27:7-10.

Keil D.J. y Stuessy T.F. 1975. Chromosome counts of Compositae from the United States, Mexico and Guatemala. Rhodora 77:171-195.

Kimball R.T. y Crawford D.J. 2004. Phylogeny of Coreopsideae (Asteraceae) using ITS sequences suggests lability in reproductive characters. Molecular Phylogenetics and Evolution 33:127-139. 
Lawrence W.J.C. 1929. The genetic and cytology of Dahlia species. Journal of Genetics 2:125-159.

McVaugh R. 1984. Compositae. En: Anderson W. Ed. Flora NovoGaliciana XII. A descriptive account of the vascular plants of Western Mexico, pp. 262-281, University of Michigan Press, Ann Arbor.

Melchert T.E. 1967. Systematic studies in the Coreopsidinae (Compositae): new Cosmos from Mexico. Sida 3:170-176.

Melchert T.E. 1968. Systematic studies in the Coreopsidinae: cytotaxonomy of Mexican and Guatemalan Cosmos. American Journal of Botany 55:345-353.

Melchert T.E. 1975. New combinations in the Coreopsidinae. Phytologia 32:291-298.

Melchert T.E. 1976. Cosmos. En: Nash D.L. y Williams L.O. Eds. Flora de Guatemala. Fieldiana: Botany 24:229-234.

Melchert T.E. 1990a. New names and combinations in Cosmos (Asteraceae, Coreopsideae). Phytologia 68:189-199.

Melchert T.E. 1990b. Cosmos caudatus (Asteraceae: Coreopsideae) in México: a cytotaxonomic reappraisal. Phytologia 69:200-215.

Melchert T.E. 1990c. Cosmos ocellatus, a Bidens (Asteraceae, Coreopsideae). Phytologia 69:436-444.

Melchert T.E. 2010a. Chromosome counts of Bidens, Cosmos and Thelesperma species (Asteraceae, Coreopsidinae). Phytologia 92:312-333.

Melchert T.E. 2010b. Cosmos. En: Turner B.L. Ed. The Comps of Mexico A Systematic Account of the Family Asteraceae (Chapter 10: subfamily Coreopsideae), Phytologia Memoirs Vol. 15, pp. 82-105, Texensis Publishing, Gruver.

Melchert T.E. y Turner B.L. 1990. New species, names and combinations in Mexican Bidens (Asteraceae: Coreopsideae). Phytologia 69:20-31.

Moreno N.P. 1984. Glosario Botánico Ilustrado. Instituto Nacional de Investigaciones sobre Recursos Bióticos, Xalapa.

Mort M.E., Randle C.P., Kimball R.T., Tadesse M. y Crawford D.J. 2008. Phylogeny of Coreopsideae (Asteraceae) inferred from nuclear and plastid DNA sequences. Taxon 57:109-120.

Müntzing A. 1936. The evolutionary significance of autopolyploidy. Hereditas 21:263-378.

Muñiz-Mendoza R. 2008. Análisis filogenético preliminar del género Cosmos (Asteraceae) con base en secuencias del ADN ribosomal (ITS). Tesis de licenciatura, Centro Universitario de Cienias Biológicas y Agropecuarias. Universidad de Guadalajara, Guadalajara, 38 pp. <http://biblioteca.cucba.udg.mx:8080/ xmlui/bitstream/handle/123456789/5042/Muniz_Mendoza_ Rodolfo.pdf?sequence $=1>($ consultado 6 julio 2013).

Novara L.J. y Gutiérrez D.G. 2010. Asteraceae Bercht. \& Presl, Tr. V. Heliantheae Cass. Flora del Valle de Lerma 9:1-201.

Panero J.L. 2007. Tribe Coreopsideae. En: Kubitzki K., Kaderit J.W. y Jeffrey C. Eds. The Families and Genera of Vascular Plants Vol. VIII. Flowering Plants, Eudicots, Asterales, pp. 406-417, Springer-Verlag, Berlín.

Panero J.L. y Funk V.A. 2002. Toward a phylogenetic subfamilial classification for the Compositae (Asteraceae). Proceedings of the Biological Society of Washington 115:909-922.

Panero J.L. y Villaseñor J.L. 1996. Novelties in Asteraceae from southern Mexico. Brittonia 48:79-90.

Robinson B.L. 1909. Diagnoses and transfers of the Tropical American phanerogams. Proceedings of the American Academy of Arts and Sciences 44:613-626.
Robinson H. 1981. A revision of the tribal and subtribal limits of the Heliantheae (Asteraceae). Smithsonian Contributions to Botany 51:1-102.

Robinson H., Powell A.M., King R.M. y Weedin J.F. 1981. Chromosome numbers in Compositae, XII: Heliantheae. Smithsonian Contributions to Botany 52:1-28.

Ryding O. y Bremer K. 1992. Phylogeny, distribution and classification of the Coreopsideae (Asteraceae). Systematic Botany 17:649-659.

Rzedowski J. y Calderón de Rzedowski G. 2008. Compositae. Tribu Heliantheae I (géneros Acmella - Jefea). Flora del Bajio y Regiones Adyacentes 157:1-344.

Semple J.C. y Watanabe K. 2009. A review of chromosome numbers in Asteraceae with hypotheses on chromosomal base number evolution. En: Funk V.A., Susanna A., Stuessy T. y Bayer R.J. Eds. Systematics, Evolution and Biogeography of the Compositae, pp. 61-72, International Association of Plant Taxonomy, Universidad de Viena, Viena.

Sherff E.E. 1917. Studies in the genus Bidens. IV. Botanical Gazette 64:21-41.

Sherff E.E. 1923. New or otherwise noteworthy Compositae. Botanical Gazette 76:78-94.

Sherff E.E. 1925. New or otherwise noteworthy Compositae. II. Botanical Gazette 80:367-389.

Sherff E.E. 1926. Cosmos blakei, a new species from Guatemala. Botanical Gazette 82:333-335.

Sherff E.E. 1929. New or otherwise noteworthy Compositae. III. Botanical Gazette 88:285-309.

Sherff E.E. 1930. New or otherwise noteworthy Compositae. IV. Botanical Gazette 89:362-373.

Sherff E.E. 1932. Revision of the genus Cosmos. Field Museum of Natural History, Botanical Series 8:401-447.

Sherff E.E. 1936. Additions to the genus Euphorbia L. and to certain genera of the Compositae. Botanical Gazette 97:580-609.

Sherff E.E. 1937. Certain new plants from Hawaii and Mexico. American Journal of Botany 24:88-90.

Sherff E.E. 1955. Cosmos. En: Sherff E.E. y Alexander E.J. Eds. North America Flora, Compositae-Heliantheae-Coreopsidinae, pp. 130-146, The New York Botanical Garden, Nueva York.

Sherff E.E. 1959. Notes on Coreopsidinae from Mexico and the United States. Brittonia 11:188-190.

Sherff E.E. 1962. New Coreopsidinae from Mexico and the United States. Brittonia 14:172-173.

Sherff E.E. 1964. Some new or otherwise noteworthy Coreopsidinae (Compositae) from Mexico. Brittonia 16:58-73.

Smith E.B. 1975. The chromosome numbers of North American Coreopsis with phyletic interpretations. Botanical Gazette 136:78-86.

Soltis D.E. y Soltis P.S. 1999. Polyploidy: recurrent formation and genome evolution. Trends in Ecology and Evolution 14:348352 .

Soltis D.E., Albert V.A., Leebens-Mack J., Bell C.D., Paterson A.H., Zheng C., Sankoff D., dePamphilis C.W., Wall P.K. y Soltis P.S. 2009. Polyploidy and angiosperm diversification. American Journal of Botany 96:336-348.

Stebbins G.L. 1938. Cytological characteristics associated with the different growth habits in the dicotyledons. American Journal of Botany 25:189-198.

Strother J.L. 1983. More chromosome studies in Compositae. American Journal of Botany 70:1217-1224. 
Strother J.L. 1999. Compositae-Heliantheae s.l. En: Daniel T.F. Ed. Flora de Chiapas Vol. 5, pp. 1-232. California Academy of Sciences, San Francisco.

Strother J.L. y Panero J.L. 2001. Chromosome studies: Mexican Compositae. American Journal of Botany 88:499-502.

Sundberg S., Cowan C.P. y Turner B.L. 1986. Chromosome counts of Latin American Compositae. American Journal of Botany 73:33-38.

Tadesse M., Crawford D.J. y Kim S.C. 2001. A cladistic analysis of morphological features in Bidens L. and Coreopsis L. (Asteraceae-Heliantheae) with notes on generic delimitation and systematics. En: Friis I. y Ryding O. Eds. Biodiversity Research in the Horn of Africa Region, pp. 85-102, Biologiske Skrifter, The Royal Danish Academy of Sciences and Letters, Copenague.

Thiers B. 2013. Index Herbariorum: A global directory of public herbaria and associated staff. New York Botanical Garden's Virtual Herbarium. <http://sweetgum.nybg.org/ih/> (consultado 9 mayo 2014).

Recibido: 23 de agosto de 2013

Aceptado: 26 de octubre de 2013
Turner B.L., Beaman J.H. y Rock H.F.L. 1961. Chromosome numbers in the Compositae. V. Mexican and Guatemalan species. Rhodora 63:121-129.

Turner B.L., Powel A.M. y King R.M. 1962. Chromosome numbers in the Compositae. VI. Additional Mexican and Guatemalan species. Rhodora 64:251-271.

Vargas-Amado G., Castro-Castro A., Harker M., Villaseñor J.L., Ortiz E. y Rodríguez A. 2013. Distribución geográfica y riqueza del género Cosmos (Asteraceae: Coreopsideae). Revista Mexicana de Biodiversidad 84:536-555.

Watanabe K. 2013. Index to Chromosome Numbers in Asteraceae <http://www.lib.kobe-u.ac.jp/infolib/meta_pub/ G0000003asteraceae_e> (consultado 11 junio 2013).

Wood T.E., Takebayashi N., Barker M.S., Mayrose I., Greenspoon P.B. y Rieseberg L.H. 2009. The frequency of polyploid speciation in vascular plants. Proceedings of the National Academy of Sciences of de United States of America 106:13875-13879. 
Apéndice 1. Clave para la identificación de las especies de Cosmos.

1. Plantas anuales; tallo ramificado por arriba de la mitad del eje principal; rizoma ausente; raíz axonomorfa con múltiples ramificaciones laterales (Cosmos sección Cosmos).

2. Hojas bipinnatisectas; segmentos linear-filiformes, 0.1-2 mm de ancho; filarias externas lanceolado-subuladas; flores liguladas de color blanco, violeta o purpúreo claro.

3. Capítulos de 4-9 cm de diám. (incluidas las lígulas extendidas); flores liguladas 8(10-12); lígulas 3-5 cm long., más largas que las filarias externas; amplia distribución en América .................................................................... C. bipinnatus 3. Capítulos de 0.5-2.5 cm diám. (incluidas las lígulas extendidas); flores liguladas 5-8; lígulas 0.3-1.5 cm long., más cortas que las filarias externas; desde el SSO de E.U.A. hasta el NO y el Altiplano Central de México C. parviflorus 2. Hojas 2-3 pinnatisectas; segmentos lanceolados, 2-11 mm de ancho; filarias externas lineares a lanceoladas; flores liguladas de color violeta o anaranjado.

4. Flores liguladas de color anaranjado C. sulphureus

4. Flores liguladas de color blanco a violeta.

5. Capítulos de 4-8 cm diám. (incluidas las lígulas extendidas); lígulas más largas que las filarias externas; filarias externas pubescentes; de la vertiente del Pacífico en México C. pacificus 5. Capítulos de 2-4 cm diám. (incluidas las lígulas extendidas); lígulas con frecuencia más cortas que las filarias externas; filarias externas glabrescentes; de la vertiente Atlántica desde México a Brasil y por la Pacífica desde México hasta Perú C. caudatus

1. Plantas perennes, leñosas o herbáceas; tallos ramificados desde la base o por debajo de la mitad del eje principal; rizoma presente; raíces adventicias robustas o tuberosas.

6. Rizomas con raíces adventicias robustas a manera de un xilopodio; hábito sufrútice; tallo 4-6 angulado o terete, leñoso hacia la base; hojas en su mayoría coriáceas, profundamente pinnatisectas o linear-enteras; segmentos lineares, 1.5-10 cm long., 1-5 mm lat.; filarias externas e internas 5-8; flores liguladas 5 u 8(10), de color amarillo, purpúreo claro, violeta o blanco; aquenios en su mayoría híspidos (Cosmos sección Mesinenia).

7. Flores del disco de color blanco, rosa pálido, translúcidas u ocroleucas; polen de color blanco.

8. Hojas membranáceas, todas 1-3 pinnatisectas; segmentos de las hojas lineares, 0.2-0.7 mm lat.; flores del disco translúcidas o de color blanco; filarias internas 5; del oeste de la Faja Volcánica Transmexicana, sur de la Sierra Madre Occidental y noroeste de la Sierra Madre del Sur (Jalisco, Michoacán, Nayarit, Durango, Zacatecas, Sinaloa), México C. carvifolius 8. Hojas rígidas, las caulinares simples, a veces las basales pinnatisectas, 1-5 mm de ancho; flores del disco de color rosa pálido, ocroleuco o rara vez blanco; filarias internas 5-8; de la Sierra Madre Occidental (Chihuahua, Durango, Nayarit, Sinaloa y Sonora), México.

9. Hojas 2-5 mm lat.; filarias externas 8-10 y las internas 8; flores liguladas 8-10, de color rosa; flores del disco 25-

35 , de color rosa pálido; ramas del estigma de color purpúreo C. linearifolius 9. Hojas 0.5-2 mm lat.; filarias externas 5(8-9) y las internas 5(-8); flores liguladas 5, de color violeta; flores del disco 10-20, de color ocroleuco a blanco; ramas del estigma de color rojizo .................... C. ochroleucoflorus 7. Flores del disco y polen de color amarillo.

10. Hojas 5-15 cm long.; flores liguladas 5-8(-10), de color violeta a purpúreo intenso; amplia distribución en México, Guatemala, Honduras, Nicaragua y Costa Rica ..... C. crithmifolius 10. Hojas 2-7.5 cm long.; flores liguladas 5, de color blanco, violeta claro o amarillo; distribución restringida a Jalisco y Nayarit, México.

11. Lígulas de color violeta, rara vez blanco; hojas 2-6.5 cm long., 2-5.5 cm ancho, con segmentos marcadamente falciformes; del occidente Jalisco y sur de Nayarit C. intercedens 11. Lígulas de color amarillo, blanco o rosa pálido; hojas 2-7.5 cm long., 1.5-6.5 ancho, con segmentos lineares a ligeramente falciformes; del centro de Jalisco ..... C. landii 6. Rizoma corto con raíces tuberosas o rizoma largo con raíces adventicias de apariencia fibrosa; hábito herbáceo; tallos teretes; hojas membranáceas, simples, lobadas, pinnatífidas, pinnatisectas o pinnadas; segmentos de las hojas variables; filarias externas e internas 8-10; flores liguladas 8(10-12), de color purpúreo claro a intenso, violeta o blanco; aquenios hispidos o glabros (Cosmos sección Discopoda).

12. Plantas semiacuáticas; rizoma largo con raíces adventicias de apariencia fibrosa; filarias externas elíptico-obovadas, obtusas; flores liguladas de color blanco; aquenios exaristados; del occidente de Jalisco, México C. mevaughii 12. Plantas terrestres; rizoma corto con raíces tuberosas; filarias externas triangular estrechas, lanceoladas, 
ensiformes o truladas, acuminadas; flores liguladas de color purpúreo, violeta o blanco; aquenios en su mayoría aristados; amplia distribución desde México hasta Argentina.

13. Plantas escaposas a subescaposas; capítulos 1(3-5); pedúnculos 10-45 cm long.; pecíolos 1.5-9(15) cm long., con frecuencia más largos que las hojas.

14. Filarias externas 1.0-2.5 cm long., 0.3-0.6 cm ancho; de Argentina, Bolivia y Perú

C. peucedanifolius

14. Filarias externas $0.5-1.0 \mathrm{~cm}$ long., 0.1-0.3 cm ancho; de México y Guatemala.

15. Flores del disco de color atropurpúreo; de Guanajuato, Hidalgo, Querétaro y San Luis Potosí,

México

C. atrosanguineus

15. Flores del disco de color amarillo; amplia distribución.

16. Hojas bipinnadas, rara vez tripinnadas, raquis no alado, folíolos folíolos 1.5-5 mm ancho; pecíolos 1.5-7(-9) cm long., tan largos como las láminas; filarias externas 6-8, linear lanceoladas; aquenios exaristados; del oeste de Jalisco, México C. deficiens 16. Hojas simples, pinnatífidas o pinnadas, raquis parcialmente alado; folíolos $0.5-2.5 \mathrm{~cm}$ ancho; pecíolos 3-15 cm long., más cortos que las láminas (cuando son más largos que las láminas, el folíolo terminal es dentado y dos veces más largo que los folíolos laterales); filarias externas 8-10, oblongolanceoladas a oblanceoladas o lineares; aquenios 2-4(-6) aristados; del centro y sur de México hasta Guatemala.

17. Hojas simples, pinnatífidas o pinnadas; folíolos iguales, margen entero; filarias externas oblongolanceoladas a oblanceoladas; desde el oriente, centro y sur de México hasta Guatemala

C. diversifolius

17. Hojas pinnadas; folíolo terminal más largo que los laterales, margen denticulado; filarias exter-

nas linear-lanceoladas; de Taxco, Guerrero, México C. schaffnerii

13. Plantas caulescentes; capítulos 3-6(-9); pedúnculos 10-20(-40) long.; pecíolos 0.5-2(-4) cm long., más cortos que las hojas o sésiles.

18. Flores del disco de color amarillo.

19. Capítulos con lígulas deflexas, en ocasiones ligeramente extendidas; hojas pinnatisectas; de Oaxaca, México.

20. Pecíolo 0.7-2 cm long., no alado; capítulos 3-18, 2-4 cm diám. incluidas las lígulas; filarias externas 5-9 mm long., 1-2 mm ancho; flores liguladas de color atropurpúreo, glabras; lígulas 1.2-1.6 cm long.; flores del disco 18-32; aquenios 1-1.3 long., 1-2 mm ancho; de Juxtlahuaca, Oaxaca, México C. juxtlahuacensis 20. Pecíolo 1.5-2.5 cm long., alado; capítulos solitarios, 4.5-7.5 cm diám. incluidas las lígulas; filarias externas 1-2.5 cm long., 5-7 mm ancho; flores liguladas de color rojo intenso, aterciopeladas; lígulas 2-2.5 cm long.; flores del disco 51-80; aquenios 1.5-2.5 cm long., 2-3 mm ancho; de Zimatlán, Oaxaca, México .....

C. nelsonii

19. Capítulos con lígulas extendidas; hojas simples, lobadas, pinnatífidas o pinnatisectas; amplia distribución en México.

21. Hojas sésiles o con pecíolos de $3 \mathrm{~mm}$ long.

22. Flores liguladas de color violeta; flores del disco 50-80; filarias externas 3-4 mm ancho, con 5 canales resiníferos conspicuos en la cara abaxial; de Guachinango, Jalisco, México C. pseudoperfoliatus

22. Flores liguladas de color violeta o atropurpúreo; flores del disco 10-30; filarias externas 1-1.5 mm ancho, con 3 canales resiníferos conspicuos en la cara abaxial; de Jalisco y Michoacán, México.

23. Hojas con lóbulos enteros; lóbulos 5-8 mm ancho C. sessilis

23. Hojas con lóbulos 1-divididos; lóbulos 1-3 mm ancho C. stellatus

21. Hojas con pecíolos de 1-4(-9) cm long.

24. Hojas simples o pinnatisectas; segmentos lineares.

25. Pedúnculos $15-30 \mathrm{~cm}$ long.; flores del disco $25-30$ C. palmeri

25. Pedúnculos $30-40 \mathrm{~cm}$ long.; flores del disco 35-50 C. pringlei 
24. Hojas bipinnatisectas a tripinnatisectas; segmentos linear-lanceolados a lanceoladoestrechos u oblanceolados.

26. Aquenios tuberculados; aristas caedizas.

27. Hojas de 10-23 cm long.; pecíolos 3-9 cm long.; segmentos terminales de 0.3-1 cm lat.; flores liguladas de color atropurpúreo a purpúreo rojizo; de Ayutla, Jalisco, México C. longipetiolatus 27. Hojas de 5-7(10) cm long.; pecíolos 1.5-3 cm long.; segmentos terminales de 1-2 mm lat.; flores liguladas de color violeta; de Santiago Tenango, Oaxaca, México C. sherffii

26. Aquenios lisos; aristas persistentes.

28. Tallos grisáceo-puberulentos; hojas con envés de color ferrugíneo y haz de color verde claro; del sur del Estado de México, México C. modestus 28. Tallos glabros; hojas de color verde concoloras; de Durango, Jalisco, Nayarit y Zacatecas, México C. montanus

18. Flores del disco de color purpúreo o amarillo con lóbulos de color purpúreo.

29. Serie de páleas externas formando un tubo que envuelve y aísla a las flores del disco.

30. Plantas acaulescentes, escaposas a subscaposas; pedúnculos de $30-60 \mathrm{~cm}$ long.; aquenios fusiformes; de la Sierra Madre Oriental en Guanajuato, Hidalgo, Querétaro y San Luis Potosí, México C. atrosanguineus 30. Plantas caulescentes; pedúnculos $15-27 \mathrm{~cm}$ de long.; aquenios fusiformefalcados; de la Sierra Madre del Sur en Coahuayutla, Guerrero, México ... C. mattfeldii

29. Serie de páleas externas sin envolver a las flores del disco.

31. Lígulas de color violeta; aquenios lisos.

32. Hojas bipinnadas; folíolos ovado romboides a ovado deltoides, glabrescentes en ambas caras, folíolo terminal más grande que los laterales, márgenes con 4-5 dientes concentrados hacia la base; de Sultepec, Estado de México, México C. nitidus 32. Hojas pinnadas; folíolos ovado lanceolados, hirsutos en ambas caras, folíolos semejantes, enteros o con 1-4 dientes concentrados hacia el ápice; del Estado de México, Guerrero y Morelos, México

C. purpureus

31. Lígulas de color purpúreo claro o atropurpúreo; aquenios muriculados. 33. Filarias externas ovadas a deltoides; de la Sierra Madre Occidental en Durango y Zacatecas, México .... C. concolor 33. Filarias externas linear-lanceoladas; de la Faja Volcánica Transmexicana.

34. Hojas simples, lobadas o pinnadas; pecíolo 3-5 mm long.; de Chiapas, Distrito Federal, Durango, Estado de México, Jalisco, Michoacán, Morelos, Nayarit, Puebla, Tlaxcala, Veracruz y Zacatecas, México C. scabiosoides 34. Hojas simples, lobadas, pinnadas, pinnatisectas o ternadas; pecíolo 0.8-3.0 cm long. o ausente; de Jalisco, México.

35. Hojas ternadas, pubescentes, membranáceas, 2-4 cm long.; pecíolo 0.8-2.5 cm long.; de Atenguillo y Mascota, Jalisco, México. C. jaliscensis

35. Hojas pinnatisectas, glabras, coriáceas, 4-14 cm long.; pecíolo 2.0-3.0 cm long.; de Zapopan, Jalisco, México

C. ramirezianus 
Arturo Castro-Castro et al.

Apéndice 2. Variación morfológica en hojas, filarias y flores del disco en Cosmos sección Discopoda.

\begin{tabular}{|c|c|c|c|}
\hline Especie & Hojas & Filarias & Flores del disco \\
\hline C. atrosanguineus & $\begin{array}{l}\text { Basales o caulinares; pecíolo 5.0-8.0 mm, } \\
\text { alado; lámina 3.0-7.0 cm, ovada a elíptica, } \\
\text { aguda, cuneado-decurrente, simple, lobulada en } \\
\text { la base, pinnada o trifoliolada, membranácea; } \\
\text { folíolos 3-7, ovado-romboides, cuneados, el } \\
\text { terminal a menudo trilobado, } 2.0-5.0 \mathrm{~cm} \times \\
\text { 1.5-4.5 cm, verde oscuros en el haz, pálidos } \\
\text { en el envés, pubescentes o glabros. }\end{array}$ & $\begin{array}{l}\text { Externas } 8,7.0-10.0 \mathrm{~mm} \text {, } \\
\text { oblongas a oblanceoladas, } \\
\text { 7-15 nervadas, verdes o } \\
\text { púrpura; internas } 8, \\
\text { 10-13 mm, lanceolado- } \\
\text { ovadas, púrpura sobre } \\
\text { todo hacia la porción } \\
\text { distal, ápice glabro. }\end{array}$ & $\begin{array}{l}\text { 30-50, tubulares, } 7.0-8.0 \text { mm, } \\
\text { amarillas con lóbulos púrpuras; } \\
\text { lóbulos pubescentes en su cara } \\
\text { interna y ciliados, glabras; } \\
\text { tubo glabro. }\end{array}$ \\
\hline C. concolor & $\begin{array}{l}\text { Caulinares; pecíolo 3.0-7.0 mm, alado; lámina } \\
\text { 3.0-7.0 cm, ovada a elíptica, aguda, cuneado- } \\
\text { decurrente, simple, pinnada o bipinnatisecta, } \\
\text { membranácea; folíolos 3-5, ovado-romboides, } \\
\text { cuneados, a veces dentados en la mitad superior, } \\
\text { 1.5-3.0 cm × 1.5-4.5 cm, verdes oscuros en el haz, } \\
\text { pálidos en el envés, pubescentes o glabros. }\end{array}$ & $\begin{array}{l}\text { Externas 7-8, 6.0-7.0 mm, } \\
\text { ovadas a oblanceoladas, } \\
\text { 7-10 nervadas, verdes; } \\
\text { internas 8, 8-9 mm, ovadas, } \\
\text { púrpura, ápice glabro. }\end{array}$ & $\begin{array}{l}\text { 20-30, infundibuliformes, } \\
\text { 7.0-8.0 mm, púrpuras; lóbulos } \\
\text { glabros; tubo piloso. }\end{array}$ \\
\hline C. deficiens & $\begin{array}{l}\text { Basales; pecíolo } 1.5-3.5 \mathrm{~cm} \text {; lámina } 2.0-5.0 \mathrm{~cm} \text {, } \\
\text { ovada a romboide, aguda, obtusa, 2-3-pinnada, } \\
\text { membranácea; folíolos 3-7, ovados, obtusos, } \\
2-5 \mathrm{~cm} \times 0.5-1.5 \mathrm{~cm} \text {; foliolulos 3-5, lanceolados, } \\
\text { agudos, cuneados, } 0.5-1.0 \mathrm{~cm} \times 0.2-0.5 \mathrm{~cm} \text {, verdes, } \\
\text { pubescentes en ambas caras. }\end{array}$ & $\begin{array}{l}\text { Externas 6-8, 4.0-7.5 mm, } \\
\text { lanceoladas a lineares, sin } \\
\text { nervaduras, verdes; las } \\
\text { internas 5-8, 7-9 mm, } \\
\text { elípticas, translúcidas, pero } \\
\text { los ápices púrpura y con un } \\
\text { mechón de pelos. }\end{array}$ & $\begin{array}{l}\text { 30-40, infundibuliformes, } \\
\text { 5.0-7.0 mm, amarillas; lóbulos } \\
\text { ciliados; tubo glabro. }\end{array}$ \\
\hline C. diversifolius & $\begin{array}{l}\text { Basales o caulinares; pecíolo 2.0-9.0 cm, alado; } \\
\text { lámina 2.0-8.0 cm, espatulada o elíptica, aguda o } \\
\text { redondeada, cuneada, simple o pinnatisecta, } \\
\text { membranácea; folíolos 3-7(-9), ovados a lineares, } \\
\text { 0.5-3.5 cm × 0.2-1.5 cm, enteros o a veces alguno } \\
\text { provisto de uno o dos lóbulos, verdes en el haz, } \\
\text { pálidos en el envés, glabros o glabriúsculos. }\end{array}$ & $\begin{array}{l}\text { Externas 6-10, 7.0-12.5 mm, } \\
\text { lanceoladas u ovadas, 5-7 } \\
\text { nervadas, verdes pero } \\
\text { amarillentas hacia la base; } \\
\text { internas 8, 9.0-13.0 mm, } \\
\text { elípticas, translúcidas, pero } \\
\text { los ápices púrpura, 8-13 } \\
\text { nervadas, ápice con un } \\
\text { mechón de pelos púrpura. }\end{array}$ & $\begin{array}{l}\text { 35-50, infundibuliformes, } \\
\text { 7.0-10 mm, amarillas; lóbulos } \\
\text { ciliados; tubo glabriúsculo. }\end{array}$ \\
\hline C. jaliscensis & $\begin{array}{l}\text { Caulinares; pecíolo 0.8-2.5 cm; lámina 2.0-4.5 cm, } \\
\text { ovado-deltoide, aguda, cuneada, pinnada, } \\
\text { membranácea; folíolos 3, ovados, cuneados, dentados } \\
\text { en la mitad superior, } 1.0-4.5 \mathrm{~cm} \times 1.0-2.5 \mathrm{~cm} \text {, verdes } \\
\text { oscuros en el haz, pálidos en el envés, pubescentes. }\end{array}$ & $\begin{array}{l}\text { Externas 8, 4.5-10.0 mm, } \\
\text { lineares, 3-5 nervadas, } \\
\text { verdes; internas } 8,5.0- \\
10.0 \text { mm, elípticas u ovadas, } \\
\text { translúcidas, 8-15 finamente } \\
\text { nervadas, ápices con un } \\
\text { mechón de pelos. }\end{array}$ & $\begin{array}{l}\text { 15-35, tubulares, } 6.0-8.0 \text { mm, } \\
\text { amarillas con lóbulos púrpuras; } \\
\text { lóbulos ciliados; tubo glabro. }\end{array}$ \\
\hline C. juxtlahuacensis & $\begin{array}{l}\text { Caulinares; pecíolo 0.7-2.0 cm; lámina 2.5-7.5 cm, } \\
\text { ovada a deltoide, aguda, bipinnada o tripinnada, } \\
\text { membranácea; folíolos 5-7, ovados; foliolúlos } \\
\text { lanceolados, agudos, cuneados, lobados, } 0.5-3.5 \mathrm{~cm} \times \\
0.5-2.5 \mathrm{~cm} \text {, verdes, ciliados, glabriúsculos. }\end{array}$ & $\begin{array}{l}\text { Externas 6-8, 5.0-9.0 mm, } \\
\text { lanceoladas, } 5 \text { nervadas, } \\
\text { verdes; internas 8, 8.0-11.0 } \\
\text { mm, elípticas u ovadas, } \\
\text { translúcido grisáceas, 10-15 } \\
\text { finamente nervadas, ápice } \\
\text { glabro. }\end{array}$ & $\begin{array}{l}\text { 18-32, tubulares, } 6.0-7.0 \mathrm{~mm} \text {, } \\
\text { amarillas; lóbulos ciliados; tubo } \\
\text { piloso. }\end{array}$ \\
\hline
\end{tabular}


Apéndice 2. Continuación.

\begin{tabular}{|c|c|c|c|}
\hline Especie & Hojas & Filarias & Flores del disco \\
\hline C. longipetiolatus & $\begin{array}{l}\text { Caulinares; pecíolo (3.0-)6.0-9.0 cm, alado; lámina } \\
2.0-16.0 \mathrm{~cm} \text {, ovada, aguda a redondeada, bipinnada } \\
\text { o tripinnada, membranácea; folíolos 3-5, ovados, } \\
\text { cuneados, lobados, } 1.0-7.5 \mathrm{~cm} \times 0.5-1.5 \mathrm{~cm} \text {, } \\
\text { segmentos terminales de } 0.3-1 \mathrm{~cm} \text { de ancho, verdes, } \\
\text { ciliados, glabriúsculos. }\end{array}$ & $\begin{array}{l}\text { Externas 8, 8.0-11.0 mm, } \\
\text { lineares, 3-5 nervadas, } \\
\text { verdes; internas 8, 7.0-14.0 } \\
\text { mm, elípticas a lanceoladas, } \\
\text { translúcido amarillentas, } \\
\text { 20-25 finamente nervadas, } \\
\text { ápice con un mechón de } \\
\text { pelos púrpura. }\end{array}$ & $\begin{array}{l}\text { 40-50, tubulares, } 5.0-6.5 \mathrm{~mm} \text {, } \\
\text { amarillas; lóbulos pubescentes } \\
\text { en su cara interna y ciliados; } \\
\text { tubo piloso. }\end{array}$ \\
\hline C. mattfeldii & $\begin{array}{l}\text { Caulinares; pecíolo } 2.5-4.0 \mathrm{~cm} \text {; lámina } 5.0-8.5 \mathrm{~cm} \text {, } \\
\text { lanceolada a ovada, aguda, pinnada, membranácea; } \\
\text { folíolos 3-5, ovado, cuneados, dentados, } 2.0-3.0 \mathrm{~cm} \times \\
0.8-1.5 \mathrm{~cm} \text {, verde oscuros en el haz y verde pálidas y } \\
\text { ferrugíneas en el envés, ciliados, glabros. }\end{array}$ & $\begin{array}{l}\text { Externas 8-9, 8.0-11.0 mm, } \\
\text { lanceoladas, } 5 \text { nervadas, } \\
\text { verdes; internas 8, 8.0-14.0 } \\
\text { mm, elípticas a lanceoladas, } \\
\text { translúcido purpureas, 10-15 } \\
\text { finamente nervadas, ápice } \\
\text { con un mechón de pelos } \\
\text { púrpura. }\end{array}$ & $\begin{array}{l}\text { 30-40, infundibuliformes, } 7.0 \text { - } \\
8.5 \mathrm{~mm} \text {, amarillas en su tubo y } \\
\text { purpuras en la porción distal; } \\
\text { lóbulos pubescentes en su cara } \\
\text { interna y ciliados; tubo glabro. }\end{array}$ \\
\hline C. mcraughii & $\begin{array}{l}\text { Caulinares; pecíolo } 1.5-3.5 \mathrm{~cm} \text {; lámina 5.0-10.0 cm, } \\
\text { ovada, aguda, obtusa, pinnada, membranácea; } \\
\text { folíolos 3-11, elípticos a lanceolados, } 1.0-5.0 \mathrm{~cm} \times \\
0.2-0.7 \mathrm{~cm} \text {, verdes, ciliados, glabros. }\end{array}$ & $\begin{array}{l}\text { Externas 8-12, 5.0-8.0 mm, } \\
\text { elípticas a obovadas, verdes; } \\
\text { internas 8, 8.0-10.0 mm, } \\
\text { elípticas, translúcido } \\
\text { grisáceas, 10-12 finamente } \\
\text { nervadas, ápice con un } \\
\text { mechón de pelos blancos. }\end{array}$ & $\begin{array}{l}\text { 50-65, tubulares, } 7.0-8.0 \mathrm{~mm} \text {, } \\
\text { amarillas; lóbulos pubescentes } \\
\text { en su cara interna y ciliados; } \\
\text { tubo piloso. }\end{array}$ \\
\hline C. modestus & $\begin{array}{l}\text { Caulinares; pecíolo } 0.7-1.5 \mathrm{~cm} \text {; lámina } 5.0-6.5 \mathrm{~cm} \text {, } \\
\text { ovada, aguda o redondeada, cuneada, pinnada, } \\
\text { membranácea; folíolos 3-7, lanceolados o romboides, } \\
\text { dentados, } 1.0-4.0 \mathrm{~cm} \times 0.5-1.5 \mathrm{~cm} \text {, verdes y } \\
\text { glabriúsculos en el haz y pilosos y ferrugíneos en el } \\
\text { envés, ciliados. }\end{array}$ & $\begin{array}{l}\text { Externas 6-8, lanceoladas, } \\
\text { 5.0-7.0 mm, verdes, } 3-5 \\
\text { nervadas; internas } 8,8.0- \\
10.0 \text { mm, lanceolado-ovadas, } \\
\text { translúcido amarillentas, } \\
\text { 12-15 finamente nervadas, } \\
\text { ápice con un mechón de } \\
\text { pelos púrpura. }\end{array}$ & $\begin{array}{l}\text { 25-35, infundibuliformes, } 5.0 \text { - } \\
6.0 \text { mm, amarillas; lóbulos } \\
\text { pubescentes en su cara interna } \\
\text { y ciliados; tubo piloso. }\end{array}$ \\
\hline C. montanus & $\begin{array}{l}\text { Caulinares; pecíolo } 0.5-2.5 \mathrm{~cm} \text {; lámina } 4.0-9.0 \mathrm{~cm} \text {, } \\
\text { ovada o deltoide, aguda, cuneada, simple o pinnada, } \\
\text { membranácea; folíolos 5-10, lanceolados o lineares, } \\
\text { lobados o dentados, } 1.0-5.0 \mathrm{~cm} \times 0.3-0.6 \mathrm{~cm} \text {, verdes } \\
\text { glabros, ciliados. }\end{array}$ & $\begin{array}{l}\text { Externas } 8,4.5-7.0 \mathrm{~mm} \text {, } \\
\text { lineares o lanceoladas, } \\
\text { verdes o púrpuras, } 3-5 \\
\text { nervadas; internas } 8,8.0- \\
12.0 \mathrm{~mm} \text {, elípticas, } \\
\text { translucidas o púrpuras, } \\
\text { 10-15 finamente nervadas, } \\
\text { ápice con un mechón de } \\
\text { pelos púrpura. }\end{array}$ & $\begin{array}{l}25-45 \text {, infundibuliformes, } 6.0- \\
7.0 \mathrm{~mm} \text {, amarillas; lóbulos } \\
\text { pubescentes en su cara interna } \\
\text { y ciliados; tubo glabro. }\end{array}$ \\
\hline
\end{tabular}


Apéndice 2. Continuación.

\begin{tabular}{|c|c|c|c|}
\hline Especie & Hojas & Filarias & Flores del disco \\
\hline C. nelsonii & $\begin{array}{l}\text { Caulinares; pecíolo 0.5-2.0 cm; lámina } 4.5-8.0 \text { cm, } \\
\text { deltoide, aguda, decurrente, pinnada o bipinnada, } \\
\text { membranácea; folíolos 3-5, deltoides; foliolúlos } \\
\text { lanceolados, cuneados, lobados, } 1.0-2.0 \mathrm{~cm} \times 0.3-0.8 \\
\mathrm{~cm} \text {, verdes pálidos y glabriúsculos en el haz y verde } \\
\text { ferrugíneos en el envés, ciliados. }\end{array}$ & $\begin{array}{l}\text { Externas } 8,7.5-10.0 \mathrm{~mm} \text {, } \\
\text { linear-oblongas, verdes, 5-7 } \\
\text { nervadas; internas } 8,8.0- \\
12.0 \mathrm{~mm} \text {, ovado-oblongas, } \\
\text { translucido grisáceas, } 10-15 \\
\text { finamente nervadas, ápice } \\
\text { glabro. }\end{array}$ & $\begin{array}{l}\text { 45-80, tubulares, } 10.0-12.0 \mathrm{~mm} \text {, } \\
\text { amarillas; lóbulos pubescentes } \\
\text { en su cara interna y ciliados; } \\
\text { tubo piloso. }\end{array}$ \\
\hline C. nitidus & $\begin{array}{l}\text { Caulinares; pecíolo 2.0-14.0 cm; lámina 4.5-12.0 cm, } \\
\text { romboide, acuminada, cuneada, pinnada, } \\
\text { membranácea; folíolos 3-5, deltoides o romboides, } \\
\text { acuminados, cuneados, } 2.0-3.5 \mathrm{~cm} \times 0.5-1.8 \mathrm{~cm} \text {, } \\
\text { dentados, verdes, ciliados. }\end{array}$ & $\begin{array}{l}\text { Externas 8, 5.0-6.0 mm, } \\
\text { lanceoladas, verdes, 5-9 } \\
\text { nervadas; internas 8, 6.0- } \\
7.0 \mathrm{~mm} \text {, lanceolado-ovadas, } \\
\text { translúcido grisáceas, 10-15 } \\
\text { finamente nervadas, ápice } \\
\text { con un mechón de pelos } \\
\text { púrpura. }\end{array}$ & $\begin{array}{l}\text { 20-30, infundibuliformes, } 5.0- \\
6.5 \mathrm{~mm} \text {, purpuras; lóbulos } \\
\text { pubescentes en su cara interna } \\
\text { y ciliados; tubo piloso. }\end{array}$ \\
\hline C. palmeri & $\begin{array}{l}\text { Caulinares; pecíolo 0.5-1.5 cm, alado; lámina 3.0-6.0 } \\
\text { cm, ovada, rómbica o lanceolada, aguda, cuneada, } \\
\text { simple, trifoliada, pinnada o bipinnada, membranácea; } \\
\text { folíolos lineares u oblongos, } 3.0-5.0 \mathrm{~cm} \times 1.0-7.0 \mathrm{~mm} \text {, } \\
\text { dentados, agudos, verde oscuros en el haz, verde } \\
\text { pálidos en el envés, pilosas en ambas caras o al } \\
\text { menos sobre las nervaduras. }\end{array}$ & $\begin{array}{l}\text { Externas } 8,3.0-6.0 \mathrm{~mm}, \\
\text { obovadas a deltoides, verdes, } \\
3-5 \text { inconspicuamente } \\
\text { nervadas; internas } 8,6.0 \text { - } \\
8.0 \mathrm{~mm} \text {, lanceoladas, } \\
\text { translúcidas, 8-15 finamente } \\
\text { nervadas, ápice con un } \\
\text { mechón de pelos púrpura. }\end{array}$ & $\begin{array}{l}\text { 35-45, infundibuliformes, } 7.0- \\
8.0 \text { mm, amarillas; lóbulos } \\
\text { pubescentes en su cara interna } \\
\text { y ciliados; tubo piloso. }\end{array}$ \\
\hline C. peucedanifolius & $\begin{array}{l}\text { Caulinares o basales; pecíolo 1.5-6.0 cm, alado; } \\
\text { lámina 5.0-14.0 cm, ovada, rómbica o lanceolada, } \\
\text { aguda, simple, pinnada o bipinnada, membranácea; } \\
\text { folíolos 9, lineares o lanceolados, 3.0-5.0 cm × } \\
\text { 4.0-7.0 mm, verdes, enteros, glabros. }\end{array}$ & $\begin{array}{l}\text { Externas 7-10, 7.0-29.0 mm, } \\
\text { lanceoladas u ovadas, 9-11 } \\
\text { nervadas, verdes; internas } \\
\text { 7-8, 5.0-12.0 mm, elípticas, } \\
\text { translúcido violadas, 8-13 } \\
\text { finamente nervadas, ápice } \\
\text { con un mechón de pelos } \\
\text { púrpura. }\end{array}$ & $\begin{array}{l}\text { 35-65, infundibuliformes, } 6.0 \text { - } \\
8.5 \mathrm{~mm} \text {, amarillas; lóbulos } \\
\text { pubescentes en su cara interna } \\
\text { y ciliados; tubo piloso. }\end{array}$ \\
\hline C. pringlei & $\begin{array}{l}\text { Caulinares; pecíolo 0.5-2.5 cm, alado; lámina } \\
\text { 3.0-19.0 cm, ovada, rómbica o lanceolada, aguda o } \\
\text { redondeada, simple, lobada o pinnada, membranácea; } \\
\text { folíolos lineares, enteros, agudos, 3.0-5.0 cm × } \\
\text { 4.0-7.0 mm, verdes, glabros. }\end{array}$ & $\begin{array}{l}\text { Externas 6-8, 7.0-11.0 mm, } \\
\text { lanceoladas, 5-8 nervadas, } \\
\text { verdes; internas 7-8, 7.0- } \\
12.0 \mathrm{~mm} \text {, lanceoladas, } \\
\text { translúcidas, 8-11 finamente } \\
\text { nervadas, ápice con un } \\
\text { mechón de pelos púrpura. }\end{array}$ & $\begin{array}{l}\text { 45-55, infundibuliformes, } 8.0- \\
9.5 \mathrm{~mm} \text {, amarillas; lóbulos } \\
\text { pubescentes en su cara interna } \\
\text { y ciliados; tubo piloso. }\end{array}$ \\
\hline C. pseudoperfoliatus & $\begin{array}{l}\text { Caulinares; sésiles; lámina 4.5-7.5 cm, ovada o } \\
\text { deltoide, aguda o redondeada, obtusa, simple, } 3 \\
\text { lobada o pinnatifida, membranácea; lóbulos } \\
\text { lanceolados, enteros, redondeados o agudos, 3.5-7.0 } \\
\mathrm{cm} \times \text { 2.0-2.5 mm, verdes, pilosos y ciliados. }\end{array}$ & $\begin{array}{l}\text { Externas 7-8, 6.0-7.5 mm, } \\
\text { lanceoladas, inconspicua- } \\
\text { mente } 3 \text { nervadas, verdes; } \\
\text { internas 8, 6.5-9.0 mm, } \\
\text { lanceoladas, translúcidas, no } \\
\text { nervadas, ápice con un } \\
\text { mechón de pelos púrpura. }\end{array}$ & $\begin{array}{l}\text { 50-80, tubulares, } 6.0-7.5 \mathrm{~mm} \text {, } \\
\text { amarillas; lóbulos ciliados; } \\
\text { tubo piloso. }\end{array}$ \\
\hline
\end{tabular}


Apéndice 2. Continuación.

\begin{tabular}{|c|c|c|c|}
\hline Especie & Hojas & Filarias & Flores del disco \\
\hline C. purpureus & $\begin{array}{l}\text { Caulinares; pecíolo } 0.5-1.5 \mathrm{~cm} \text {; lámina } 4.5-9.5 \mathrm{~cm} \text {, } \\
\text { deltoide, aguda, bipinnada o trifoliada, membranácea; } \\
\text { folíolos ovados, enteros o lobados, } 1.0-2.0 \mathrm{~cm} \times \\
5.0-14.0 \mathrm{~mm} \text {, verdes, pilosos. }\end{array}$ & $\begin{array}{l}\text { Externas 7-8, 6.0-8.0 mm, } \\
\text { lineares, 3-5 nervadas, verdes; } \\
\text { internas 8, 6.5-9.0 mm, } \\
\text { lineares, translúcidas, 6-13 } \\
\text { nervadas, ápice con un } \\
\text { mechón de pelos púrpura. }\end{array}$ & $\begin{array}{l}\text { 25-30, infundibuliformes, } 6.0- \\
7.5 \mathrm{~mm} \text {, púrpuras o tubo } \\
\text { blanquecino con lóbulos } \\
\text { púrpura; lóbulos ciliados; } \\
\text { tubo piloso. }\end{array}$ \\
\hline C. ramirezianus & $\begin{array}{l}\text { Caulinares; pecíolo 2.0-3.0 cm; lámina 10.0-20.0 cm, } \\
\text { deltoide, aguda, pinnatisecta, coriácea; segmentos 3-7, } \\
\text { lineares, } 4.0-10.0 \mathrm{~cm} \times 2.0-5.0 \mathrm{~cm} \text {, verdes, glabros, } \\
\text { rígido ciliados. }\end{array}$ & $\begin{array}{l}\text { Externas 6-10, 4.0-9.0 mm, } \\
\text { lanceoladas, verdes, 4-5 } \\
\text { nervadas; internas 8-11, } 6.5 \text { - } \\
12.0 \mathrm{~mm} \text {, oblongo-ovadas, } \\
\text { translúcidas o a penas } \\
\text { violadas, no nervadas, ápice } \\
\text { con un mechón de pelos } \\
\text { púrpura. }\end{array}$ & $\begin{array}{l}\text { 45-50, infundibuliformes, } 7.0 \text { - } \\
7.5 \mathrm{~mm} \text {, amarillas con lóbulos } \\
\text { púrpura; lóbulos glabros; } \\
\text { tubo piloso. }\end{array}$ \\
\hline C. scabiosoides & $\begin{array}{l}\text { Caulinares; sésiles o con pecíolo de } 3-5 \mathrm{~mm} \text { y } \\
\text { alado; lámina 4.0-10.0 cm, lanceolada o obovada, } \\
\text { aguda u obtusa, simple, lobada o pinnada, } \\
\text { membranácea; folíolos 3-5, ovados, lineares, } \\
\text { lanceolados, oblongos o rómbicos, } 2.0-3.5 \mathrm{~cm} \times \\
\text { 1.0-2.5 cm, dentados, redondeados o agudos, } \\
\text { verdes, glabros o glabriúsculos en el haz, pilosos en } \\
\text { el envés, ciliados. }\end{array}$ & $\begin{array}{l}\text { Externas } 8,3.0-8.0 \mathrm{~mm} \text {, } \\
\text { triangulares a lanceoladas, } \\
\text { verdes, 1-3 nervadas; internas } \\
8,6.0-8.0 \mathrm{~mm} \text {, elípticas a } \\
\text { oblanceoladas, púrpura, } \\
\text { 12-18 nervadas, ápice con } \\
\text { un mechón de pelos púrpura. }\end{array}$ & $\begin{array}{l}\text { 25-55, infundibuliformes, } 6.0- \\
8.0 \text { mm, amarillas con los } \\
\text { lóbulos púrpura; lóbulos } \\
\text { ciliados; tubo piloso. }\end{array}$ \\
\hline C. schaffneri & $\begin{array}{l}\text { Basales o caulinares; pecíolo 3.0-7.0 cm, alado; } \\
\text { lámina } 5.5-9.5 \mathrm{~cm} \text {, ovada a elíptica, acuminada, } \\
\text { simple, lobada, pinnada o bipinnada, membranácea; } \\
\text { folíolos 3-5, obovados o lanceolados, acuminados, } \\
\text { cuneados, } 2.0-3.5 \mathrm{~cm} \times 0 .-2.0 \mathrm{~cm} \text {, dentados, } \\
\text { verdes, ciliados. }\end{array}$ & $\begin{array}{l}\text { Externas 7-9, 5.0-6.5 mm, } \\
\text { lineares, verdes con ápice } \\
\text { púrpura, 5-7 nervadas; } \\
\text { internas 8, 6.0-7.5 mm, } \\
\text { lanceoladas, translucido } \\
\text { grisáceas, 10-12 finamente } \\
\text { nervadas, ápice glabro. }\end{array}$ & $\begin{array}{l}\text { 40-60, infundibuliformes, } 6.0 \text { - } \\
6.5 \mathrm{~mm} \text {, amarillas; lóbulos } \\
\text { ciliados; tubo piloso. }\end{array}$ \\
\hline C. sessilis & $\begin{array}{l}\text { Caulinares; sésiles; lámina 1.5-4.5 cm, ovada, } \\
\text { redondeada, obtusa, 3-7 lobada, membranácea; } \\
\text { lóbulos lanceolados, enteros, redondeados o agudos, } \\
\text { 2.0-2.5 cm × 5.0-8.5 mm, verdes, ciliados. }\end{array}$ & $\begin{array}{l}\text { Externas 8, 4.0-6.5 mm, } \\
\text { lineares, 3-5 nervadas, ver- } \\
\text { des; internas 8, lanceoladas, } \\
\text { 7.5-8.5 mm, translúcido } \\
\text { grisáceas, 10-15 nervadas, } \\
\text { ápice glabro. }\end{array}$ & $\begin{array}{l}\text { 15-30, tubulares, } 5.0-5.5 \text { mm, } \\
\text { amarillas; lóbulos ciliados; } \\
\text { tubo piloso. }\end{array}$ \\
\hline C. sherffii & $\begin{array}{l}\text { Caulinares; pecíolo } 1.0-3.0 \mathrm{~cm} \text {; lámina } 5.0-10.0 \mathrm{~cm} \text {, } \\
\text { ovada a romboide, agudas, bipinnada o tripinnada, } \\
\text { membranácea; folíolos 3-5, ovados, agudos, cuneados, } \\
\text { 3-5 lobados, } 2.5-4.5 \mathrm{~cm} \times 1.0-2.5 \mathrm{~cm} \text {, segmentos } \\
\text { terminales de } 1-2 \mathrm{~mm} \text { de ancho, verdes, lisos, glabros. }\end{array}$ & $\begin{array}{l}\text { Externas 8, 5.0-8.0 mm, } \\
\text { lineares, 3-5 nervadas, ver- } \\
\text { des; internas 8, 9.0-11.5 mm, } \\
\text { lanceoladas, translúcido } \\
\text { amarillentas o grisáceas, } \\
\text { 10-15 finamente nervadas, } \\
\text { ápice glabro. }\end{array}$ & $\begin{array}{l}\text { 20-30, tubulares, } 5.5-7.5 \mathrm{~mm} \text {, } \\
\text { amarillas; lóbulos ciliados; } \\
\text { tubo piloso. }\end{array}$ \\
\hline
\end{tabular}


Arturo Castro-Castro et al.

Apéndice 2. Continuación.

\begin{tabular}{llll}
\hline Especie & Hojas & Filarias & Flores del disco \\
\hline C. stellatus & Caulinares; sésiles; lámina 1.5-4.5 cm, ovada, aguda, & Externas 7-9, 5.0-9.5 mm, & 20-30, tubulares, 5.0-5.5 mm, \\
& obtusa, 5-7 lobada, membranácea; lóbulos lineares, & lineares, 3-7 nervadas, ver- & amarillas; lóbulos pilosos en \\
& agudos, pinnatisectos, 0.5-2.5 cm $\times 2.0-4.5 \mathrm{~mm}$, & des; internas 8, 6.5-9.5 mm, cara interna y ciliados; \\
& verdes, ciliados. & $\begin{array}{l}\text { lanceoladas, translúcido } \\
\text { grisáceas o amarillentas, } \\
\end{array}$ & tubo glabro. \\
& $6-12$ nervadas, ápice glabro. \\
\hline
\end{tabular}

